\title{
Synthesis and Optical Properties of Thiol Functionalized CdSe/ZnS (Core/Shell) Quantum Dots by Ligand Exchange
}

\author{
Huaping Zhu, ${ }^{1,2}$ Michael Z. Hu, ${ }^{1}$ Lei Shao, ${ }^{3}$ Kui Yu, ${ }^{4}$ Reza Dabestani, \\ Md. Badruz Zaman, ${ }^{4}$ and Shijun Liao ${ }^{2}$ \\ ${ }^{1}$ Oak Ridge National Laboratory, Oak Ridge, TN 37831-6181, USA \\ ${ }^{2}$ School of Chemistry and Chemical Engineering, South China University of Technology, Guangzhou 510641, China \\ ${ }^{3}$ Key Lab for Nanomaterials, Ministry of Education, Research Center of the Ministry of Education for High Gravity Engineering \\ and Technology, Beijing University of Chemical Technology, Beijing 100029, China \\ ${ }^{4}$ Steacie Institute for Molecular Sciences, National Research Council of Canada, Ottawa, ON, Canada K1A 0R6
}

Correspondence should be addressed to Michael Z. Hu; hum1@ornl.gov

Received 24 January 2014; Accepted 10 February 2014; Published 20 March 2014

Academic Editor: Binbin Weng

Copyright (C) 2014 Huaping Zhu et al. This is an open access article distributed under the Creative Commons Attribution License, which permits unrestricted use, distribution, and reproduction in any medium, provided the original work is properly cited.

\begin{abstract}
The colloidal photoluminescent quantum dots (QDs) of CdSe (core) and CdSe/ZnS (core/shell) were synthesized at different temperatures with different growth periods. Optical properties (i.e., UV/Vis spectra and photoluminescent emission spectra) of the resulting QDs were investigated. The shell-protected CdSe/ZnS QDs exhibited higher photoluminescent (PL) efficiency and stability than their corresponding CdSe core QDs. Ligand exchange with various thiol molecules was performed to replace the initial surface passivation ligands, that is, trioctylphosphine oxide (TOPO) and trioctylphosphine (TOP), and the optical properties of the surfacemodified QDs were studied. The thiol ligand molecules in this study included 1,4-benzenedimethanethiol, 1,16-hexadecanedithiol, 1,11-undecanedithiol, biphenyl-4,4'-dithiol, 11-mercapto-1-undecanol, and 1,8-octanedithiol. After the thiol functionalization, the CdSe/ZnS QDs exhibited significantly enhanced PL efficiency and storage stability. Besides surface passivation effect, such enhanced performance of thiol-functionalized QDs could be due to cross-linked assembly formation of dimer/trimer clusters, in which QDs are linked by dithiol molecules. Furthermore, effects of ligand concentration, type of ligand, and heating on the thiol stabilization of QDs were also discussed.
\end{abstract}

\section{Introduction}

Semiconductor nanocrystals or quantum dots (QDs) have received widespread and growing attention in materials application and have led to many efforts to assess nanoparticles in size-controlled manner. When the sizes of such QDs become close to or smaller than the bulk exciton Bohr radius, the electronic and optical properties of these nanomaterials show a significant change from their corresponding bulk properties, which are called quantum size effects. One such effect is the quantization of the bulk valence band and conduction band, resulting in discrete atomic-like transitions that shift to higher energies as the size of nanocrystals decreases. Because of their unique size-dependent optical and electronic properties, semiconductor nanocrystals are likely to play a key role in the emerging new field of nanotechnology, the application of which ranges from optoelectronic devices to biological fluorescence marking $[1,2]$.

In order to study the fundamental properties of these QDs and explore their use in specific applications, convenient access to ligand-stabilized QDs possessing active functional groups is essential. The lack of general synthetic strategies to introduce specific functionalities into the terminal positions of the ligand has limited detailed experimental investigations of the QD properties and reactivities [3]. QDs are not very stable in liquid solution and the underlying cause of this instability is still not totally clear. To stabilize QDs, the most common method used is chemically attaching a monolayer of organic molecules to the atoms on the surface of the nanocrystals. These organic molecules attached to 
the nanocrystals are called surfactants, capping agents, or ligands. Due to its protective or "passivation" function, this monolayer of ligands on the surface of a nanocrystal, in general, not only stabilizes QDs in a liquid solution but also improves the optical properties of the QDs.

The most highly photoluminescent (PL) QDs of CdSe and $\mathrm{CdSe} / \mathrm{ZnS}$ are typically synthesized using trioctylphosphine oxide (TOPO)/hexadecyl amine (HAD) as the surface passivation ligands $[4,5]$. However, the limited chemical functionality of the terminal position of such ligands and their restricted solution stability, especially in aqueous media, makes multistep transformations and modifications necessary in order to achieve diverse functionality. On the other hand, the variety of functionalities is available using thiol or dithiol ligands, which can be readily prepared via convenient synthetic routes and/or supplied commercially. Thiolfunctionalized QDs are known to exhibit a higher stability than the phosphine-passivated QDs, and their terminal functionalities are able to bind other molecules and substrate surfaces, making them suitable for various applications. Some studies have been conducted using thiol-based ligand molecules to modify the surfaces of QDs [6-19], most of which have focused primarily on the PL intensity of large ensembles of particles in solution $[8,10-14,18,19]$. These studies have confirmed that thiols generally quench the PL of QDs $[11,13,18]$, while primary amines can either enhance or quench the PL, depending on the amine concentration in solutions $[10,11,13,14]$. The ligand exchange approach to replace TOPO with heterobifunctional ligands such as mercapto-carbonic acids was also investigated. The thiolic end binds onto the surface of the QDs and the carboxyl moiety confers water solubility, thus making QDs adaptable to various biologically relevant environments. However, such an approach often leads to a significant loss in quantum yields and poor stability of the colloids in aqueous solutions [20, 21]. As part of our investigation to overcome these problems, we found that ligand exchange with mercaptoundecanoic acid plus further cross-linking with the amino acid lysine in the presence of dicyclohexylcarbodiimide could form a stable hydrophilic shell [22]. Such an organic functionalization reaction required only mild reaction conditions and led to QDs that were individually dispersed in water with good colloidal stability. Most importantly, the PL performance of the QDs was highly preserved and has been evaluated in the form of single-domain antibody-functionalized QDs for use in cellular imaging of cancer cells [23]. These studies provided conclusive evidence that the PL properties of QDs remain intact during ligand exchange and showed that the ligand exchange of these particles follows another pure organic pathway that is different from that of previously published approaches. Optical studies of the QDs also showed a strong dependence on the nature of the stabilizing thiol ligands. Thus the ligand exchange approach offers a new opportunity to study and tune systematically the optical and electronic properties of the QDs through measuring and controlling organic ligands bound to QDs.

Ligand-exchange reactions have become one of the most popular methods used for the surface modification of QDs, which involves the dynamic substitution of stabilizing ligands under certain conditions. This approach has been used to exchange alkanethiolates onto magnetic [24-26] and semiconductor nanoparticles [27, 28]. Alternatively, gold nanoparticles can be directly synthesized in the presence of thiolated ligands, including chemically functional species such as tiopronin, glutathione, and coenzyme A [29-31], to circumvent the need for ligand exchange. However, this approach is not well established for the high-temperature preparation of $\mathrm{CdE}(\mathrm{E}=\mathrm{S}, \mathrm{Se}, \mathrm{Te})$ type nanoparticles in hydrophobic solvents, which incorporate the ligand functionality.

In this paper, we report the general features and scope of the ligand-exchange reaction of CdSe/ZnS QDs with a variety of functionalized thiols and dithiols as surface ligands. This approach is convenient and the products tolerate organic environments (with neutral alkyl chain tails) or aqueous solutions (with charged $\mathrm{COO}^{-}$tails). Our studies show that, after the ligand exchange with thiols to replace original TOPO/TOP capping molecules, QDs exhibit significantly improved optical properties in terms of their PL emission intensity and their prolonged optical stability over time. Beyond the surface effect, the possible formation of dimers, trimers, or other self-assembly clusters by controlled molecular coupling between CeSe/ZnS QDs may offer a powerful mechanism: the ability to control the cluster size of a QDassembly system could improve PL emission and storage stability properties.

\section{Experimental Section}

2.1. Chemicals. Trioctylphosphine (TOP, 90\%), trioctylphosphine oxide (TOPO, 90\%), cadmium oxide (>99\%), toluene (99.5\%), methanol (99.93\%), octyldecylamine (ODA, 97\%), octadecene (ODE, $\geq 95.0 \%$ ), Oleic acid ( $\geq 99 \%$ ), and selenium powder were purchased from Aldrich; zinc oxide (99.9995\%) was purchased from Alfa Aesar; and sulfur $(\geq 99)$ was purchased from EM Science. All chemicals were used as received without further purification.

2.2. Synthesis of CdSe QDs. TOPO/TOP-capped CdSe quantum dots were synthesized by a procedure developed by Peng and Peng [5] and Yu et al. [32] with minor modification. Briefly, a selenium/TOP stock solution was prepared by dissolving $2 \mathrm{mmol}$ of selenium powder in $5.4 \mathrm{mmol}$ of TOP liquid with the help of ultrasonication. To dissolve $\mathrm{CdO}$ in TOPO, $0.55 \mathrm{mmol}$ of $\mathrm{CdO}$ and $10 \mathrm{mmol}$ of TOPO were placed into a $25 \mathrm{~mL}$ three-neck round-bottom glass flask and heated to $100^{\circ} \mathrm{C}$ under vacuum. While stirring with a magnetic stir bar and after replacing the vacuum with $\mathrm{N}_{2}$ gas flow, the resulting liquid melt was heated further until the temperature reached $400^{\circ} \mathrm{C}$, at which time the $\mathrm{CdO}$ dissolved well in TOPO, as indicated by the dark brownish color fading away. Simultaneously, heat was removed from the three-neck flask, and a cold (room-temperature) selenium/TOP solution in a syringe was quickly injected into the vigorously stirred $\mathrm{CdO}$ TOPO reaction mixture. A color change (from clear to deep orange) in the reaction mixture was observed within $2-5 \mathrm{~s}$, indicating the formation of $\mathrm{CdSe}$ quantum dots. The resulting 
reaction mixture was kept at a predetermined growth temperature (in the range of $150-250^{\circ} \mathrm{C}$ ). At prespecified time intervals after the injection $(10,30,60,90$, and $120 \mathrm{~min})$, crude CdSe samples were obtained by extracting an aliquot of the reaction mixture (typically $30 \mu \mathrm{L}$ ) from the flask. Each sample was diluted in $1 \mathrm{~mL}$ of toluene, purified with methanol, and redispersed in $1 \mathrm{~mL}$ of toluene.

2.3. Synthesis of CdSe/ZnS Core/Shell QDs. Core/shell CdSe/ $\mathrm{ZnS}$ quantum dots were synthesized by the procedure developed by Peng and Peng [5] and Yu et al. [32, 33] with some modification. Typically, a three-neck flask (reaction vessel) containing a mixture with $5 \mathrm{~g}$ of TOPO, $5 \mathrm{~g}$ of ODA, and $20 \mathrm{~mL}$ of $\mathrm{ODE}$ was heated to $100^{\circ} \mathrm{C}$ under vacuum for $1 \mathrm{~h}$ and then cooled to $60^{\circ} \mathrm{C}$, and $0.079 \mathrm{mmol}$ of CdSe QDs dispersed in toluene was transferred into the reaction vessel via a syringe. The toluene was removed under vacuum at $50-$ $60^{\circ} \mathrm{C}$ until bubbling in the mixture solution had ceased. The zinc precursor solution $(0.1 \mathrm{M})$ was prepared by dissolving zinc oxide $(101.7 \mathrm{mg})$ in oleic acid $(3.09 \mathrm{~g})$ and ODE $(9.0 \mathrm{~mL})$ under a $\mathrm{N}_{2}$ atmosphere at $310^{\circ} \mathrm{C}$ and then kept in an oven at about $80^{\circ} \mathrm{C}$. The sulfur precursor solution $(0.1 \mathrm{M})$ was prepared by dissolving $40.1 \mathrm{mg}$ of sulfur in $12.5 \mathrm{~mL}$ of ODE under $\mathrm{N}_{2}$ flux at $180^{\circ} \mathrm{C}$ and then cooled to room temperature. A zinc/sulfur mix solution was prepared by mixing $5 \mathrm{~mL}$ of zinc oxide solution with $5 \mathrm{~mL}$ of sulfur solution in a roundbottom flask and keeping it warm $\left(80-100^{\circ} \mathrm{C}\right)$ in a heating mantle.

The CdSe QDs mixture solution was heated under $\mathrm{N}_{2}$ flux to a desired temperature, such as $190^{\circ} \mathrm{C}$ (typical range: $135-230^{\circ} \mathrm{C}$ ). Then $1.36 \mathrm{~mL}$ of zinc/sulfur mix solution was extracted and added into the reaction vessel flask rapidly at a solution stirring speed of $1500 \mathrm{rpm}$ followed by a stirring speed of $200 \mathrm{rpm}$ for $5 \mathrm{~min}$ to complete the growth of first monolayer of $\mathrm{ZnS}$ on the $\mathrm{CdSe}$. The same procedure as above was used for the second, third, and fourth monolayers, except that $1.86,2.38$, and $3 \mathrm{~mL}$ of the zinc/sulfur mixture solution was added in the reaction vessel, respectively. Note that the quantity of ZnS used in our experiment was calculated based on the assumption that CdSe has an average diameter of 4 $\mathrm{nm}$, and four monolayers of $\mathrm{ZnS}$ are designed to be coated on CdSe cores to form particles with a diameter of $6.8 \mathrm{~nm}$ (thickness of one monolayer is $\sim 0.35 \mathrm{~nm}$ ). Therefore, the volume of individual $\mathrm{ZnS}=3.14 \times\left(6.8^{3}-4^{3}\right) / 6=131.1 \mathrm{~nm}^{3}$; the number of CdSe particles in this experiment is $7.8 \times 10^{16}$; the total volume of $\mathrm{ZnS}=131.1 \times 7.8 \times 10^{16}=1.02 \times 10^{19} \mathrm{~nm}^{3}=$ $1.02 \times 10^{-2} \mathrm{~cm}^{3}$; the $\mathrm{ZnS}$ density is $4.102 \mathrm{~g} / \mathrm{cm}^{3}$; the total mass of $\mathrm{ZnS}$ needed $=4.102 \times 1.02 \times 10^{-2}=0.042 \mathrm{~g}=4.3 \times$ $10^{-4} \mathrm{~mol}=0.43 \mathrm{mmol}$; and the needed volume of $\mathrm{ZnO}$ or sulfur solution $=0.43 \mathrm{mmol} / 0.1 \mathrm{M}=4.3 \mathrm{~mL}$. The total volume of $\mathrm{ZnO}$ and sulfur should be $8.6 \mathrm{~mL}$, which was added at four sequential times, as described above.

2.4. Optical Properties by UV/Vis and PL Spectroscopy and Quantum Yield (QY) Calculation. UV-visible spectra were collected with a Varian Cary 4E UV-Vis Spectrophotometer (Varian, Inc., USA). Photoluminescence (PL) spectra were obtained immediately after UV-Vis measurements on a FluoroMax-P photoluminescence spectrometer (Horiba Jobin Yvon Inc.), equipped with a dual monochromator on both the excitation and emission side, using a Teflon-capped quartz sample cuvette $(1 \mathrm{~cm} \times 1 \mathrm{~cm})$.

For quantum yield (QY) calculation, a Rhodamine 6G (R6G) water solution, which has a quantum yield of $95 \%$ at an excitation wavelength of $488 \mathrm{~nm}$, was used as a standard. The intersection of a QD sample with R6G was assumed to be at $X \mathrm{~nm}$ and $Y$ OD (optical density from the UV/Vis absorption spectra). $Y$ should be less than 0.2 (better less than 0.1 ), which can be achieved by diluting the sample. The QY of R6G at $X \mathrm{~nm}$ can be calculated based the following formula:

$$
\mathrm{QY}_{R-X}=\left(\frac{\mathrm{PL}_{R-X}}{\mathrm{OD}_{R-X}}\right) \times\left(\frac{\mathrm{OD}_{R 488}}{\mathrm{PL}_{R 488}}\right) \times 95 \% .
$$

The QY of QD sample at $X \mathrm{~nm}$ can be calculated as follows:

$$
\begin{aligned}
\mathrm{QY}_{\mathrm{QD}} & =\left(\frac{\mathrm{PL}_{\mathrm{QD}-X}}{\mathrm{PL}_{R-X}}\right) \times \mathrm{QY}_{R-\mathrm{X}} \\
& =\left(\frac{\mathrm{PL}_{\mathrm{QD}-X}}{\mathrm{OD}_{R-X}}\right) \times\left(\frac{\mathrm{OD}_{R 488}}{\mathrm{PL}_{R 488}}\right) \times 95 \%,
\end{aligned}
$$

where $\mathrm{OD}_{R 488}$ represents $\mathrm{OD}$ of $\mathrm{R} 6 \mathrm{G}$ at $488 \mathrm{~nm}, \mathrm{PL}_{R 488}$ represents integrated peak area of $\mathrm{R} 6 \mathrm{G}$ at the excitation of $488 \mathrm{~nm}, \mathrm{OD}_{R-X}$ represents $\mathrm{OD}$ of $\mathrm{R} 6 \mathrm{G}$ at $X \mathrm{~nm}, \mathrm{PL}_{R-X}$ represents integrated peak area of $R 6 G$ at the excitation of $X \mathrm{~nm}, \mathrm{QY}_{R-\mathrm{X}}$ represents quantum yield of $\mathrm{R} 6 \mathrm{G}$ at the excitation of $X \mathrm{~nm}, \mathrm{PL}_{\mathrm{QD}-X}$ represents integrated peak area of $\mathrm{QD}$ sample at the excitation of $X \mathrm{~nm}$, and $\mathrm{QY}_{\mathrm{QD}}$ is quantum yield of QD sample at the excitation of $X \mathrm{~nm}$.

2.5. Scanning Transmission Electron Microscope (STEM). STEM images were recorded with a Hitachi HD2000 STEM operated at an accelerating voltage of $200 \mathrm{kV}$. The samples used for STEM observations were prepared as follows. Some QD nanocrystals were dispersed in a suitable amount of toluene which was ultrasonicated for $10 \mathrm{~min}$. Then a drop of the dispersion was spread over a small SPI TEM grid (200 mesh copper grid with holey carbon film) and air dried at room temperature so that the sample deposited homogeneously on the grid between the tiny pores of the holey carbon film.

2.6. NMR Spectra. NMR spectra of ${ }^{1} \mathrm{H}$ (Bruker Advance $400 \mathrm{MHz}$ NMR spectrometer) were collected in a toluene solution using a Bruker Advance $400 \mathrm{MHz}$ NMR spectrometer. At least 64 scans were taken of each ${ }^{1} \mathrm{H}$ spectrum. ${ }^{31} \mathrm{P}$ MAS NMR spectra for CdSe and CdSe/ZnS QDs were recorded on a Varian $700 \mathrm{MHz}$ NMR spectrometer, where v0 $\left({ }^{31} \mathrm{P}\right)=283.4 \mathrm{MHz} .{ }^{31} \mathrm{P}$ MAS NMR spectra: one pulse experiment, $\pi / 2=4 \mu \mathrm{s}$, recycle delay $=60 \mathrm{~s}$, spinning at $20 \mathrm{kHz}$.

\section{Results and Discussion}

3.1. Influence of Synthesis Conditions on Optical Properties of CdSe QDs. The UV/Vis absorption spectra of CdSe QDs 
(Figure 1(a)) are red shifted (i.e., a peak shift toward a larger wavelength) with an increase in growth time, which should result from an increase in particle size with time. The particle sizes of CdSe QDs were smaller when they were synthesized at the lower growth temperature $\left(150^{\circ} \mathrm{C}\right)$, as indicated when compared to the peak positions of samples grown at the higher temperature $\left(250^{\circ} \mathrm{C}\right)$ in Figure 1(b). As the excitation wavelength increased from $320 \mathrm{~nm}$ to $482 \mathrm{~nm}$ as the PL emission spectra were being measured, all five samples were red shifted and the particle size distribution became broader with the growth time. This observation is to be supported by their PL full width at half maximum (FWHM) in wavelength units which, to some extent, can be used as an indicator of the development of the size distribution of the growing nanocrystals [34]. The values for the red shifts of the absorption and the PL emission peak positions of the growing nanocrystals as well as the increase in the PL FWHM are summarized in Table 1. The red shift of the PL emission peak position is more sensitive (i.e., bigger wavelength change for the peak shift) than that of the absorption peak position for the nanocrystals at late stages of growth [35]. Generally, PL emission peak intensity is the highest when the sample growth time is around $30 \mathrm{~min}$. Under the conditions of our synthesis, calculations of PL emission peaks of all CdSe QD samples gave quantum yields (QY) of less than approximately $4 \%$ (Figure 2). All five samples exhibited strong absorption between 500 and $600 \mathrm{~nm}$.

There are two kinds of crystal structures in the assynthesized CdSe QDs by X-ray diffraction (XRD) analysis (data not shown). One is a cubic crystal, which accounts for $60.5 \%$ of the structures, and the other is a hexagonal crystal, which accounts for $39.4 \%$.

3.2. Influence of Synthesis Conditions on Optical Properties of CdSe/ZnS (Core/Shell) QDs. The FWHM was 32.788 when the zinc and sulfur precursors were added the first time for the first $\mathrm{ZnS}$ monolayer formation (Table 2), indicating that initially the size of the particles was not uniform, but as the particles grew, they became more uniform as the FWHM decreased from 32.788 to 30.617 . However, after that the nanocrystals continued to grow, but their particle size distribution became larger again.

As the time and number of monolayers in shell increased, the PL quantum yields likewise increased. This result confirmed that the $\mathrm{ZnS}$ shell layer can improve the optical properties of quantum dots. Our experimental results showed that four monolayers of $\mathrm{ZnS}$ are suitable for the CdSe core QDs as the PL emission intensity was enhanced dramatically (Figure 3). Such PL enhancement results from the reduction of the surface defects. Detailed examination of the CdSe/ZnS (core/shell) QDs synthesized by high-resolution aberration-corrected electron microscope (ACEM) is shown in Figure 3(c). Instead of seeing epitaxial growth of crystalline structure, the shell layer outside the core seems to be of amorphous structure.

3.3. Surface Exchange and Coupling with Thiol Ligands and Their Effects on Optical Properties of CdSe/ZnS. Storage
TABLE 1: The optical properties of as-synthesized CdSe QDs with growth at $250^{\circ} \mathrm{C}$.

\begin{tabular}{lcccc}
\hline $\begin{array}{l}\text { Growth } \\
\text { time of } \\
\text { samples }\end{array}$ & $\begin{array}{c}\text { Emission } \\
\text { peak } \\
\text { area }\end{array}$ & $\begin{array}{c}\text { Full width half } \\
\text { maximum } \\
\text { (FWHM) }\end{array}$ & OD & $\begin{array}{c}\text { Quantum } \\
\text { yield (QY) }\end{array}$ \\
\hline $10 \mathrm{~min}$ & 83710 & 30.0 & 0.120 & 0.69 \\
$30 \mathrm{~min}$ & 180819 & 35.1 & 0.126 & 1.46 \\
$60 \mathrm{~min}$ & 248743 & 40.8 & 0.125 & 2.00 \\
$90 \mathrm{~min}$ & 250027 & 42.7 & 0.120 & 2.07 \\
$120 \mathrm{~min}$ & 387545 & 43.3 & 0.119 & 3.30 \\
\hline
\end{tabular}

stability of CdSe/ZnS QDs is important for the application and further modification of quantum dot systems. Purified QDs are metastable in comparison to their corresponding bulk crystals/solids and have to be kinetically stabilized. The most common method of keeping them stable is chemically attaching a monolayer of organic molecules to the atoms on the surface of nanocrystals. These organic molecules are often called ligands. In addition to serving a protective function, this monolayer of ligands on the surface of a nanocrystal provides the necessary chemical accessibility to the nanocrystals by varying the terminal groups of the ligands pointing to the outside environment. For both functions, the stability of the ligands on the surface of nanocrystals is the key concern, which ultimately determines the stability of the entire nanocrystal/ligands complex. Ligand exchange and coaction reactions are commonly employed on QDs surfaces to improve the optical properties and/or introduce functional groups on the QD surface for further reaction. TOPO is the most commonly used capping ligands in the synthesis of cadmium chalcogenide QDs, and manipulating the surface chemistry of QDs by ligand exchange is important in the application of QDs to biological systems.

Ligand exchange with thiol molecules was introduced in this work, which brings functional groups to the QD surface for further reactions, such as molecularly coupling (or linking) one QD with another QD via a thiol ligand. Thiols are probably the most commonly used ligands for stabilizing semiconductor [36-40] and noble metal [41-45] nanocrystals. They have been used almost exclusively in biomedical-related studies based on nanocrystals, so it is very important to understand the photo/chemical instability of the thiol-stabilized nanocrystals.

In this work, various types and different concentrations of thiol ligand molecules were studied and ligand-modified CdSe/ZnS QDs were measured by PL emission spectroscopy. Under certain conditions with 1,4-benzenedimethanethiol (BMT) as the ligand, significant PL emission intensity enhancement ( $>5$ times) was demonstrated (Figure 4(a)). In addition to the surface passivation effect of the thiol ligands, such enhancement may be due to controlled linking (or coupling) between CdSe/ZnS QDs via surface-exchanged thiol ligands. As we will discuss later, our STEM images do show the existence of dimers or trimers, indicating the possible molecular linkage between QDs. The ligand molecules not only exchanged with the TOPO molecules on QD 


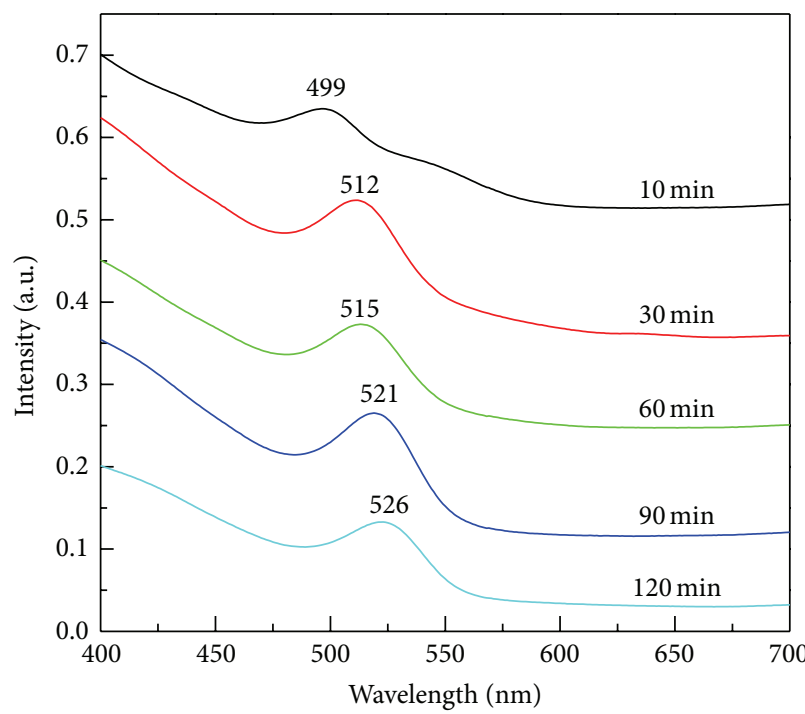

(a)

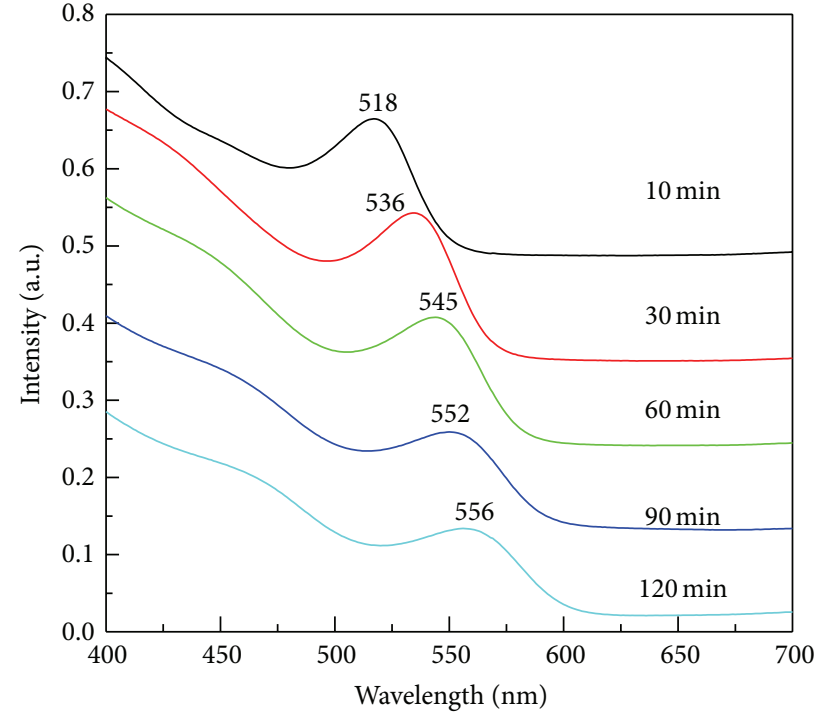

(b)

Figure 1: UV/Vis absorption spectra of CdSe QDs synthesized by modified Peng's methods [5] at different growth temperatures: (a) $150^{\circ} \mathrm{C}$ and (b) $250^{\circ} \mathrm{C}$. Aliquots were taken at different reaction times, and the reaction time for each spectrum is labeled.

TABLE 2: Quantum yield of CdSe/ZnS core/shell QDs was increased with time and with more coating of ZnS layers in shell.

\begin{tabular}{|c|c|c|c|c|}
\hline Samples & Area & FWHM & OD & QY \\
\hline As-prepared CdSe QDs, no ZnS shell layer & 49950.4 & 30.6 & 0.085 at $483 \mathrm{~nm}$ & 0.7 \\
\hline 1st $\mathrm{ZnS}$ monolayer & 466234.0 & 32.9 & 0.094 at $485 \mathrm{~nm}$ & 6.0 \\
\hline 2nd $\mathrm{ZnS}$ monolayer & 796708.1 & 31.9 & 0.097 at $485 \mathrm{~nm}$ & 10.3 \\
\hline 3rd ZnS monolayer & 868612.7 & 30.6 & 0.097 at $485 \mathrm{~nm}$ & 11.2 \\
\hline 4th $\mathrm{ZnS}$ monolayer & 975412.1 & 33.7 & 0.087 at $483 \mathrm{~nm}$ & 13.5 \\
\hline
\end{tabular}

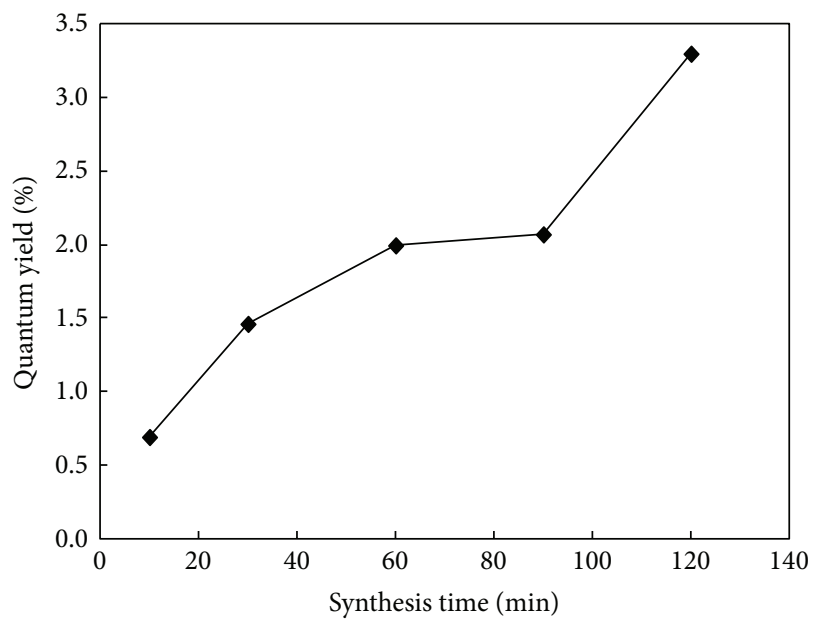

FIGURE 2: Quantum yield of CdSe QDs increases with growth time.

surfaces but also appeared to behave like a molecular linker between QDs. These controlled QD-linker-QD assemblies or aggregates could provide enhanced PL emission intensity (Figure 4). Within the concentration range we have studied (i.e., molar ratio of ligands to QDs is 1 to 7), increasing the ligand concentration clearly causes further enhancement of PL emission intensity (Figure 4(b)). Quantum yield calculation data are summarized and show the trend of QY improvement with increasing BMT concentration. Furthermore, results from systematically designed experiments for understanding the effect of various types of ligand molecules are summarized. The QY values of these measurements were derived using diluted QD samples with reasonable optical densities. No significant difference was observed in QY values among these samples except that the blank sample (with no thiol ligand addition) had a much lower QY. The QY of samples with biphenyl-4,4' -dithiol (at QDs/ligands molar ratio $>2: 1$ ) was significantly lower than that of the other samples and was in fact close to the value for blank QD sample. The QY of these samples was also significantly lower when the molar ratio of QDs to ligands was less than 2:1, which may be attributed to the poor solubility of biphenyl- $4,4^{\prime}$-dithiol in toluene. The QY of other samples increased as the concentration of ligands increased. When the ligand concentration was fixed, a higher QD concentration in the colloidal sample also led to a higher QY value. According to the above experimental results, all QY values are higher than blank sample under the same conditions if the thiol ligand/coupling agents can dissolve well in toluene solvent. As the concentration of 


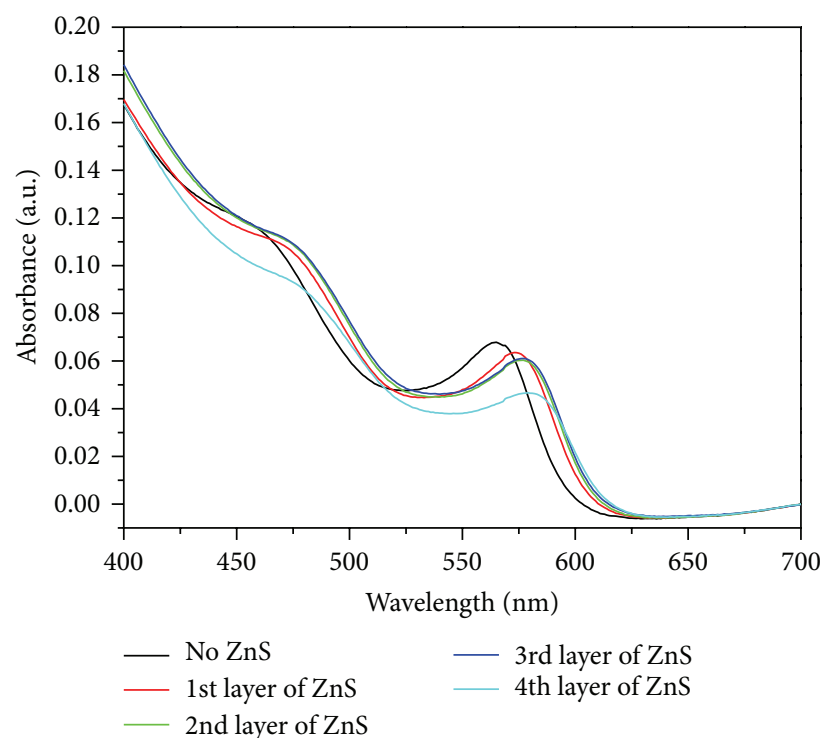

(a)

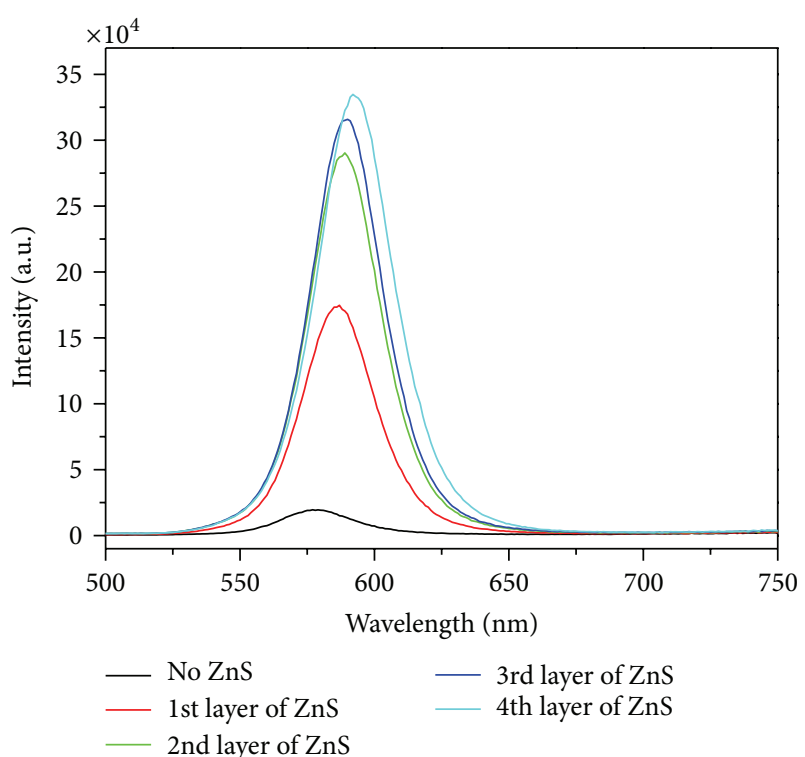

(b)

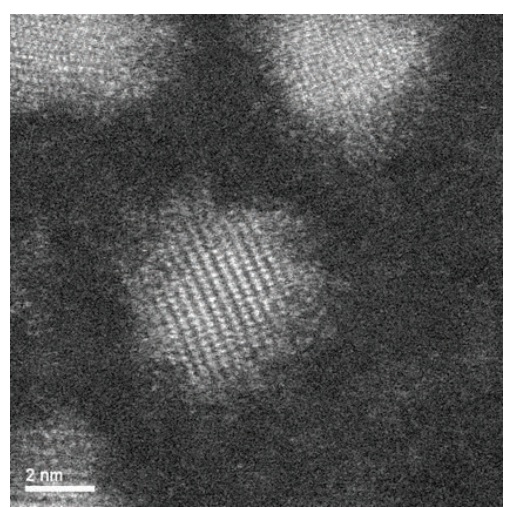

(c)

FIgURE 3: The UV/Vis absorption (a) and PL emission (b) spectra peaks are slightly red shifted with the gradual addition of ZnS shell layers on CdSe core. (c) High-resolution aberration-corrected electron microscope (ACEM) examination of a typical CdSe/ZnS (core/shell) QDs.

the coupling agent is increased, the QY value increases. If the concentration of coupling agents remains constant, the QY increases along with the QD concentration increases.

The surface traps states maybe passivated in electronically by the molecular cap species on the QD surface $[46,47]$. While X-ray diffraction and electron microscopy have been used to establish the structure of the crystalline core [48$50]$, the structure of the surface has remained largely elusive. Nuclear magnetic resonance (NMR), by virtue of probing local chemical environments, has the capability of providing important information on crystallite surfaces [51, 52]. For example, NMR has been used to explore the surface morphology of CdS nanocrystallites capped with thiophenol [52]. In this work, we focused on the NMR study of QDs surface exchanged with 1,8-octanedithiol (ODT) as ligands.

${ }^{31} \mathrm{P}$ MAS NMR spectra of CdSe and CdSe/ZnS quantum dots with and without ODT as ligands were obtained, as shown in Figure 5. The results showed that there is liquid-phase TOPO in CdSe quantum dots around $50 \mathrm{ppm}$.
The CdSe is not dry enough. It can also be seen that the peak of NMR spectra between $5 \mathrm{ppm}$ and $40 \mathrm{ppm}$ was the superimposed signal of TOPSe and TOPO [53]. With ${ }^{31} \mathrm{P}$ ${ }^{1} \mathrm{H}$ cross-polarization (CP), we can see the existence of phosphorus in CdSe quantum dots in 4 ppm, corresponding to inorganic material connected with no $-\mathrm{H}$ or $\mathrm{OH}$. With HETCOR $\left({ }^{1} \mathrm{H}_{-}{ }^{31} \mathrm{P}\right)$, the observed phosphorus in $\mathrm{CdSe} / \mathrm{ZnS}$ quantum dots at $4 \mathrm{ppm}$ was inorganic material connected to $-\mathrm{H}$ or $\mathrm{OH}$. This may result from the shell preparation procedure in which acid was used. Comparing with the results of Figure 5(b) and Figure 5(c), it can be seen part of TOPO and some of the phosphonic acid-presumably the key impurity in Tech TOPO [54] - were replaced by ODT, as the peak intensity around 28 ppm in Figure 5(b) was stronger than that in Figure 5(c) compared to the NMR peak intensity around $4 \mathrm{ppm}$, which probably explains the improvement in optical properties of quantum dots due to ligand change.

NMR spectra of an ${ }^{1} \mathrm{H}$ solution (Figure 6) can help us to understand the surface reaction effect on the optical 


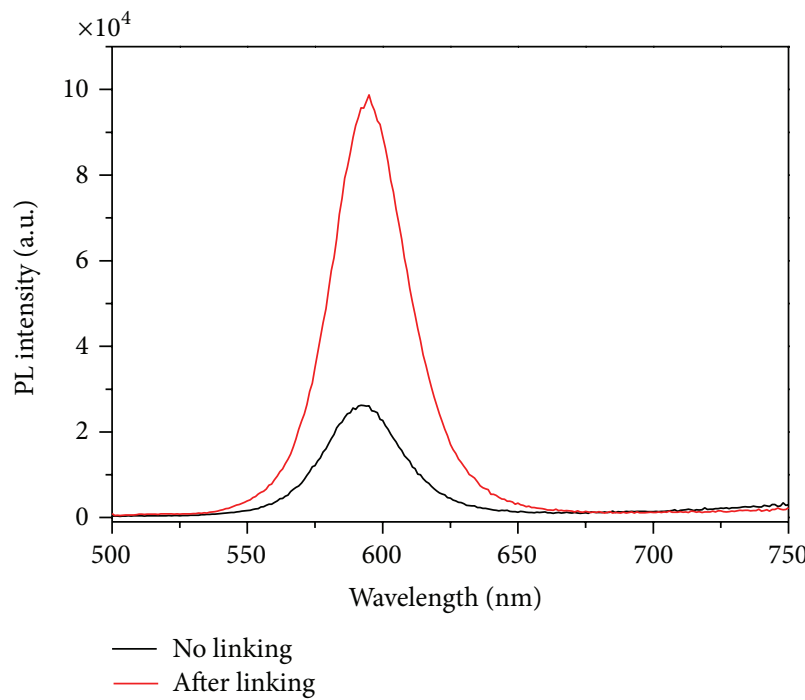

(a)

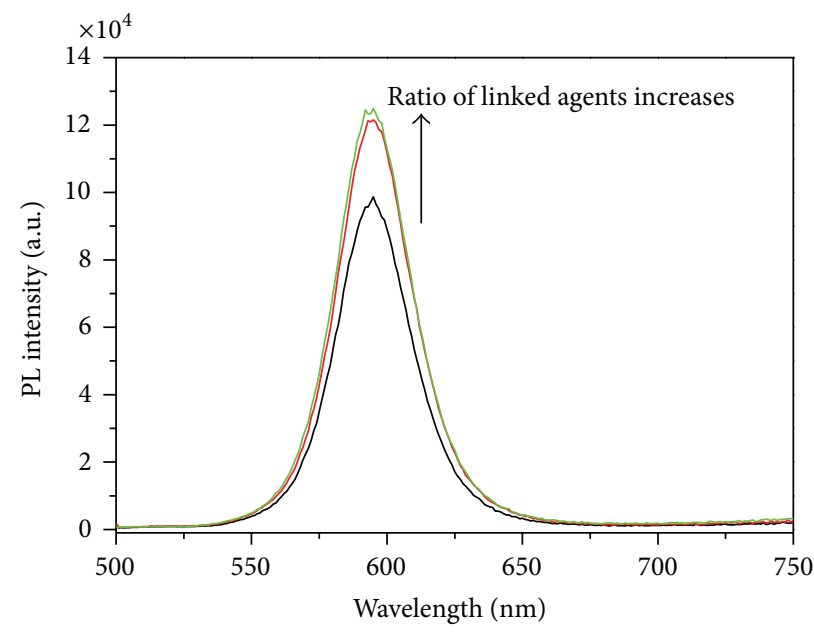

(b)

FIGURE 4: (a) Photoluminescence emission spectra of CdSe/ZnS QDs before and after being molecularly linked by 1,4-benzenedimethanethiol (molar ratio of ligands to QDs: 1/7). (b) Photoluminescence emission spectra of molecularly linked CdSe/ZnS QDs with increasing concentration of 1,4-benzenedimethanethiol (molar ratio of ligands to QDs: 1/7, 1/2, 2/1, resp.).

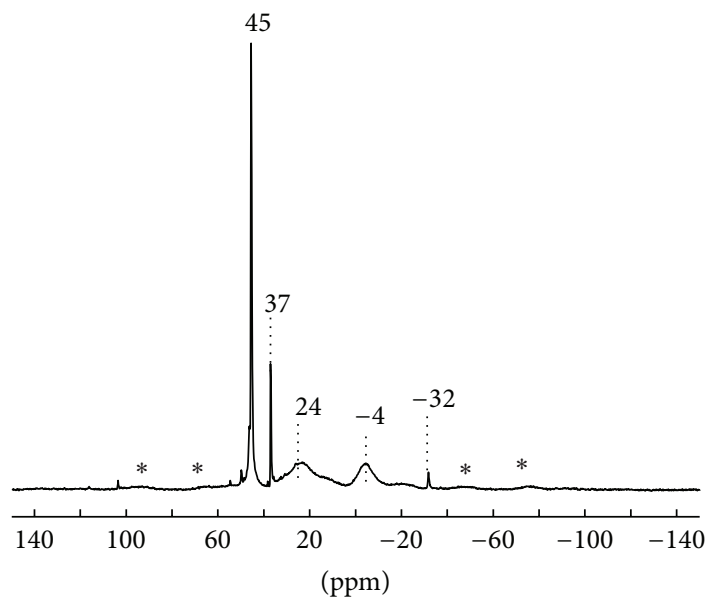

(a) CdSe quantum dots as core material

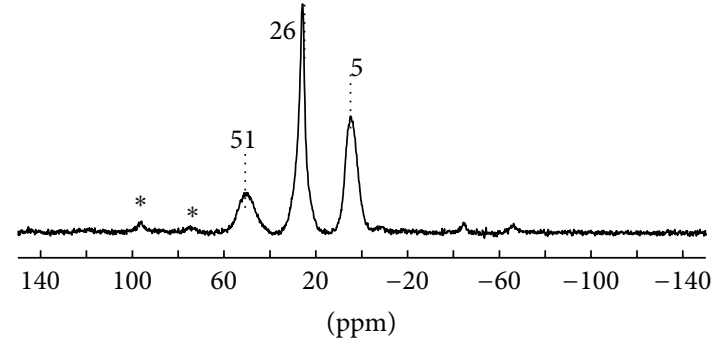

(b) CdSe/ZnS quantum dots without ODT

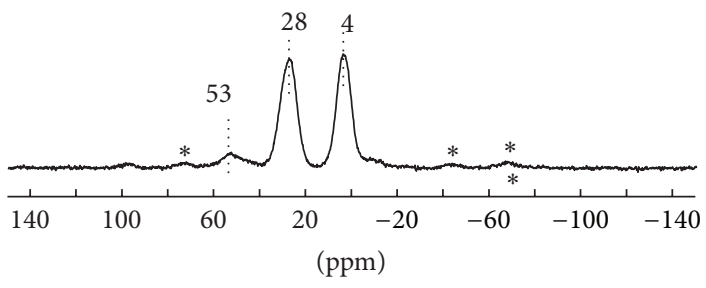

${ }^{*}$ Spinning sideband

(c) CdSe/ZnS quantum dots with ODT

FIGURE $5:{ }^{31} \mathrm{P}$ MAS NMR spectra of ligand of quantum dots. * Spinning sideband. 


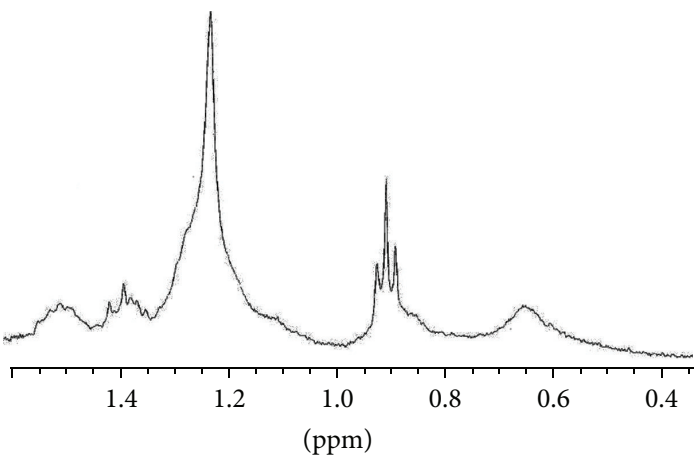

(a)

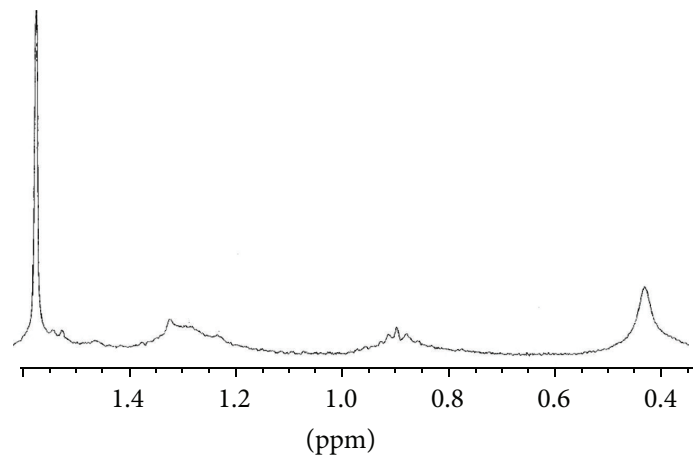

(b)

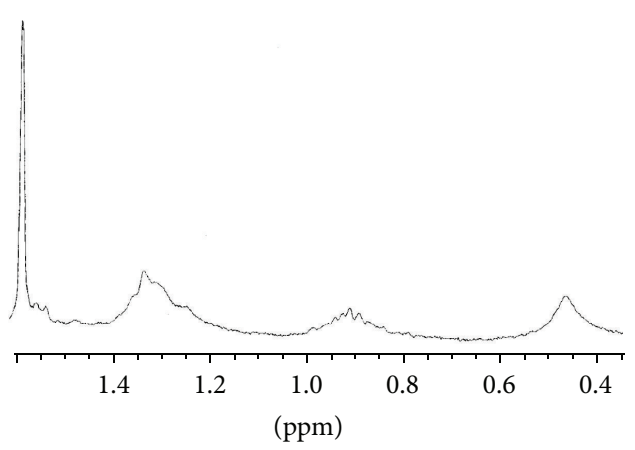

(c)

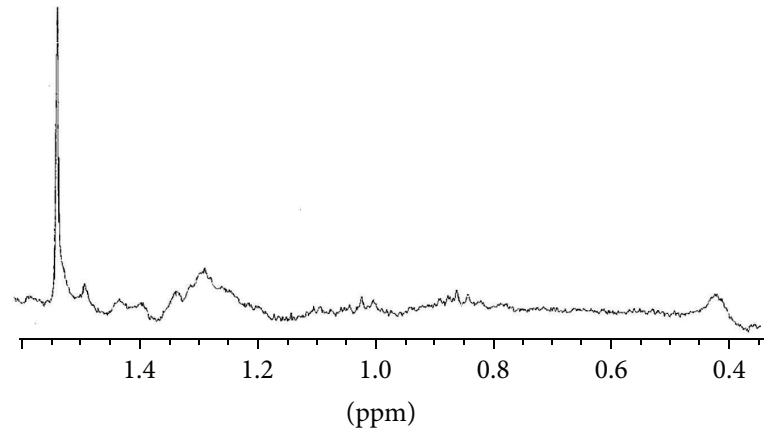

(d)

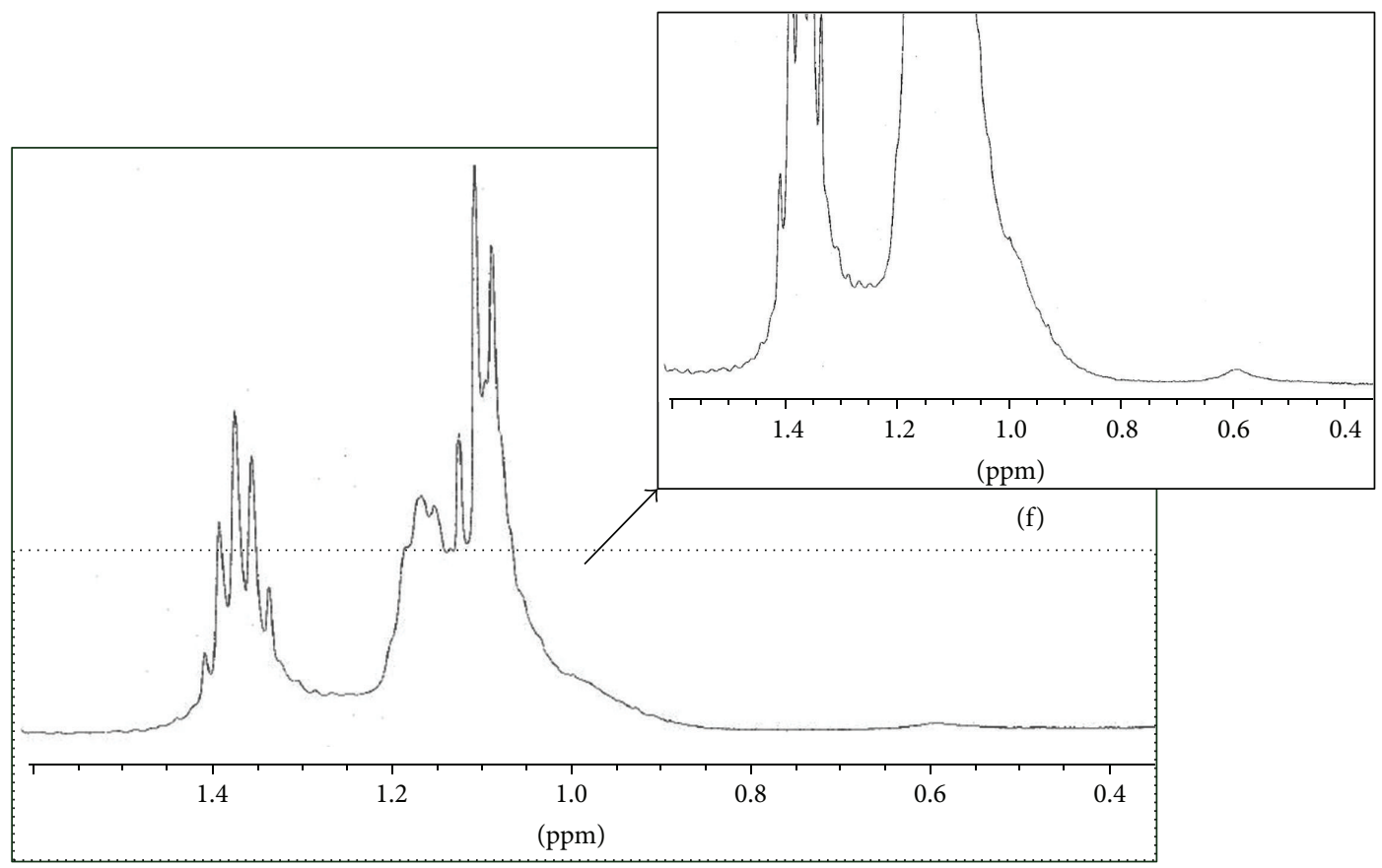

(e)

Figure 6: NMR spectra of an ${ }^{1} \mathrm{H}$ solution for (a) TOPO in toluene; (b) no ODT added, $1.82 \times 10^{-4} \mathrm{~mol} / \mathrm{L}$ of CdSe/ZnS quantum dots in toluene solution; (c) $1.82 \times 10^{-6} \mathrm{~mol} / \mathrm{L}$ of ODT in toluene solution with $1.82 \times 10^{-4} \mathrm{~mol} / \mathrm{L}$ of CdSe/ZnS quantum dots; (d) $1.82 \times 10^{-3} \mathrm{~mol} / \mathrm{L}$ of ODT in toluene solution with $1.82 \times 10^{-4} \mathrm{~mol} / \mathrm{L}$ of CdSe $/ \mathrm{ZnS}$ quantum dots; (e) Z19F4 $1.82 \times 10^{-1} \mathrm{~mol} / \mathrm{L}$ of ODT with $1.82 \times 10^{-4} \mathrm{~mol} / \mathrm{L}$ of $\mathrm{CdSe} / \mathrm{ZnS}$ quantum dots in toluene solution; (f) Z19F4 zoom $1.82 \times 10^{-1} \mathrm{~mol} / \mathrm{L}$ of ODT with $1.82 \times 10^{-4} \mathrm{~mol} / \mathrm{L}$ of CdSe/ZnS quantum dots in toluene solution. 


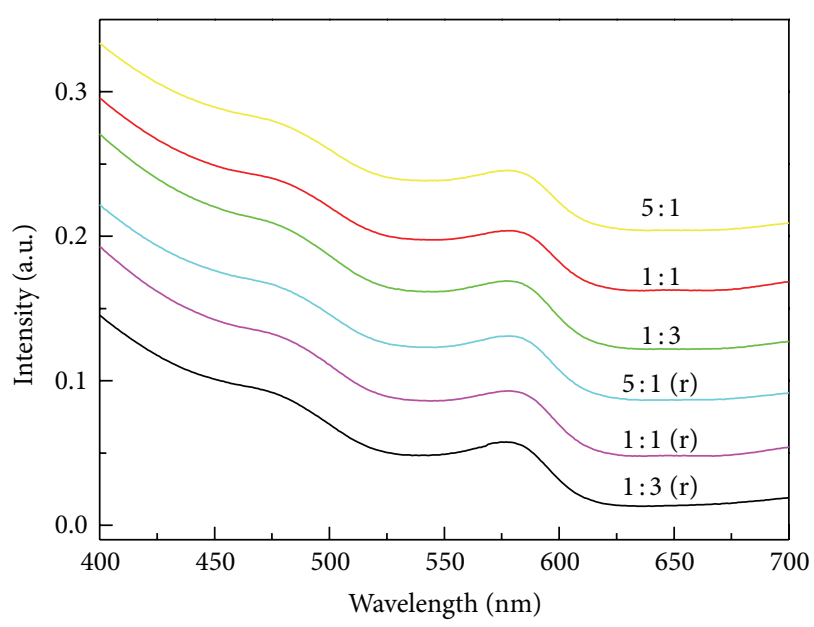

(a) UV/Vis absorption
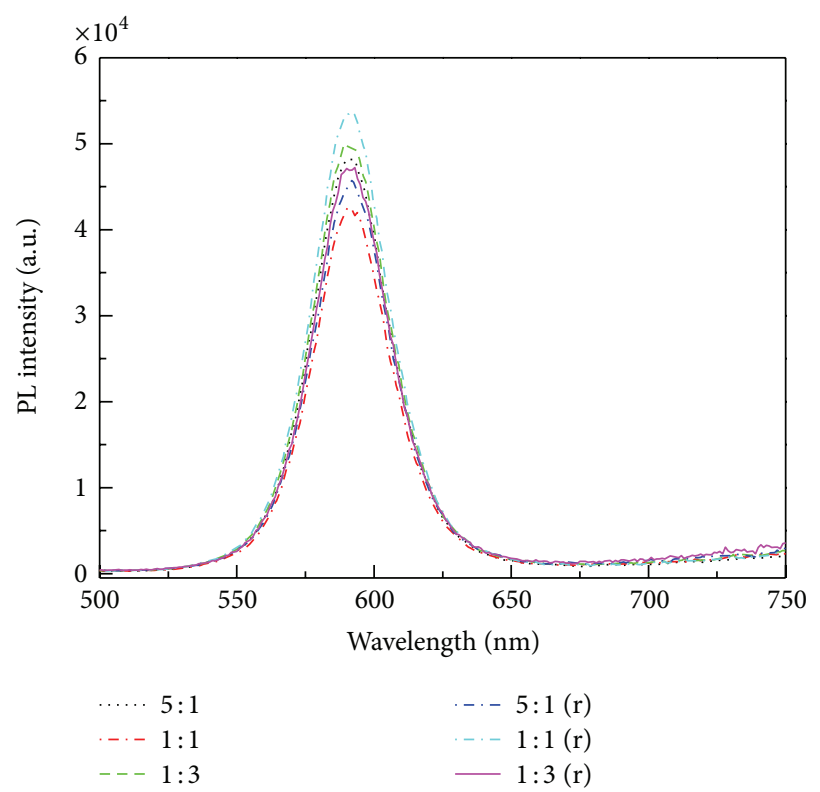

(b) Photoluminescence emissions

FIGURE 7: UV/Vis and PL emission spectra of CdSe/ZnS (core/shell) QDs linked with 1,4-benzenedimethanethiol (BMT) before and after 1 week. [The molar ratio of QDs to BMT: 5:1,1:1, and 1:3 for samples labeled as Z9D, Z9E, and Z9F, respectively. The (r) shows the repeated measurements of the same sample after 1 week.]

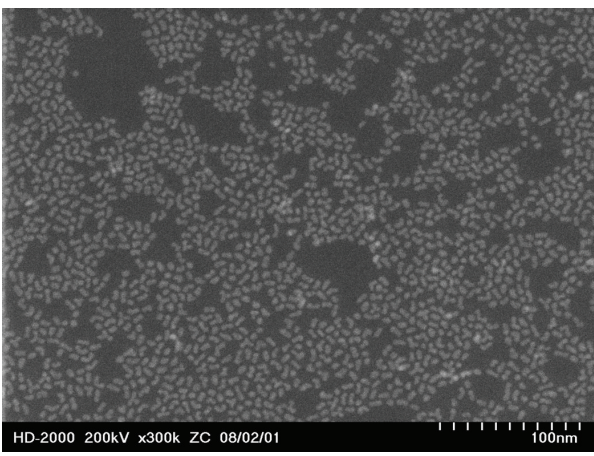

(a)

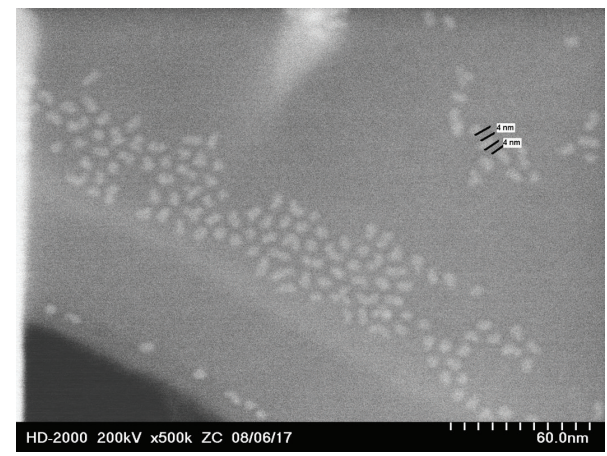

(b)

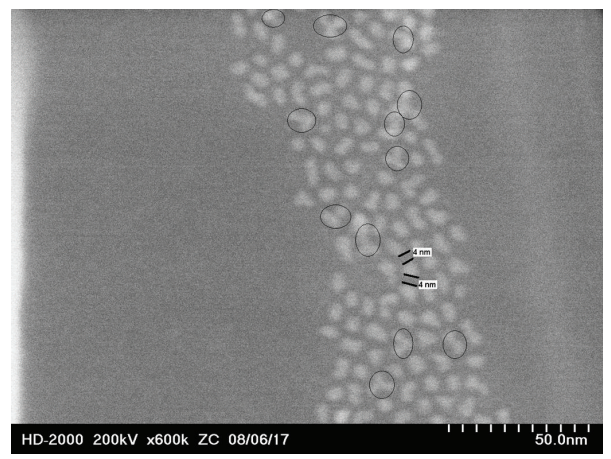

(c)

FIGURE 8: (a) STEM images of a typical molecularly linked CdSe QDs. (b) and (c) STEM images of CdSe/ZnS QDs before and after being linked by 1,16-hexadecanedithiol (HT). 


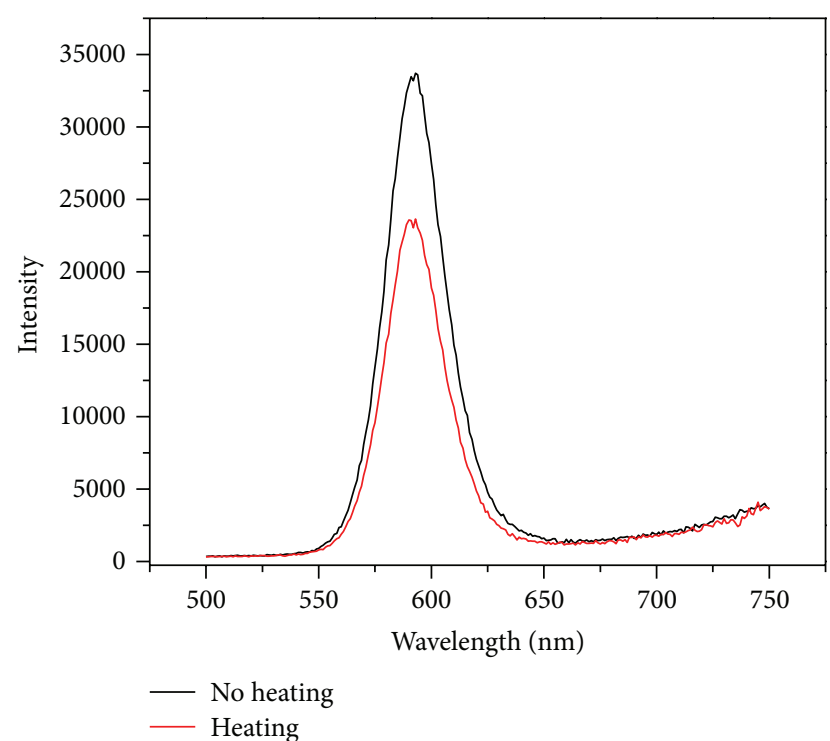

FIGURE 9: Comparison of PL emission of "unlinked" CdSe/ZnS QDs before and after heat treatment at $60^{\circ} \mathrm{C}$ for $24 \mathrm{~h}$.

properties of quantum systems. The end-chain methyl of TOPO is at $0.91 \mathrm{ppm}$ and the degenerate $\mathrm{CH}_{2} \mathrm{~s}$ are at $1.24 \mathrm{ppm}$ with separate resonances at 1.39 and $1.51 \mathrm{ppm}$ for the $\mathrm{CH}_{2} \mathrm{~s}$ at the phosphorous chain end. In the sample shown in Figure 6(b), the methyl resonance of TOPO is visible and somewhat broadened, and the chain resonances are spread out (all inequivalent). The spectra of samples in Figures 6(b) and $6(\mathrm{c})$ are almost identical, indicating that the addition of ODT at low concentration does not alter the surface of the sample, which still appears to be TOPO with no ODT. The sample in Figure 6(e) contains a large excess of ODT, and the only signals evident in the spectrum are from ODT in solution. ODT in solution has major peak multiplets at $1.10,1.15$, and $1.37 \mathrm{ppm}$. The sample of Figure $6(\mathrm{~d})$, with a concentration of ODT lower by two orders of magnitude, generates a spectrum with evidence of both TOPO and ODT in the spectrum at about the same concentration $( \pm 50 \%)$, based on the relative area of the TOPO peak at 0.91 and the ODT peak at $1.10 \mathrm{ppm}$. No free side-chain resonances and sharp peak at $1.24 \mathrm{ppm}$ are observed in the spectrum of Figure 6(d). Based on this criterion, it appears that both TOPO and ODT are attached to the surface of the quantum dots.

3.4. The Influence of Thermal Treatment on the Optical Stability of Thiol Ligand-Modified CdSe/ZnS QDs. The optical property and room-temperature stabilities of CdSe/ZnS QDs coupled with 1,4-benzenedimethanethiol (BMT) were further investigated. The results (Figure 7) showed that optical properties (in terms of PL intensity) of CdSe/ZnS QDs were stable 1 week after the ligands replacement reaction. In contrast, the PL intensity for the blank sample decayed significantly after 1 week.

The STEM examination (Figure 8) shows that the sizes of nanoparticles are somewhat bigger after $\mathrm{ZnS}$ shell growth

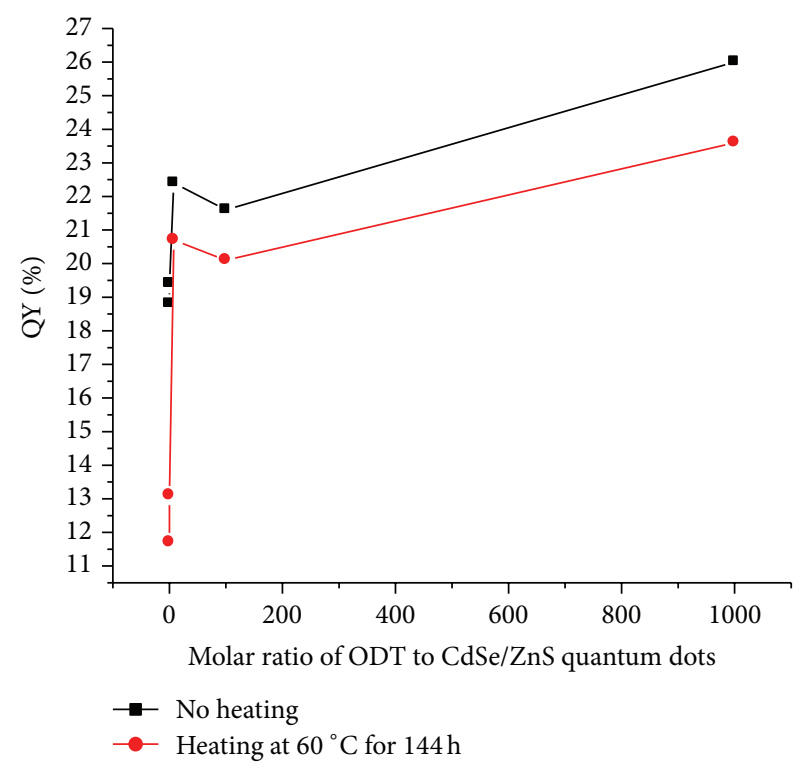

FIGURE 10: QY of CdSe/ZnS QDs at various concentrations of ODT, with and without thermal treatment.

and after the addition of thiol ligand molecules. The ligand molecules not only exchanged with the TOPO molecules on QD surfaces but also appeared to have behaved like molecular linkers between QDs. Indeed, The STEM images (Figures $8(\mathrm{a})$ and $8(\mathrm{c})$ ) indicated the existence of many dimer- and trimer-like clusters. These controlled assemblies or aggregate clusters could provide enhanced PL emission intensity.

After heat treatment, the CdSe/ZnS QDs that had no thiol ligands lost their PL emission intensity significantly (Figure 9). However, after modification, the samples with thiol ligands maintained almost the same PL emission intensity (Table 3) before and after thermal treatment at $60^{\circ} \mathrm{C}$ for $24 \mathrm{~h}$. In general (except for biphenyl-4,4'-dithiol 1:8 case), the higher the concentration of ligand agents in the QD sample, the better the maintained PL emission stability. As the molar ratio of CdSe/ZnS QDs to 1,4-benzenedimethanethiol decreased, the optical performance was enhanced. When the ratio reached $1: 2$, the optical properties of quantum dots were basically stable but were no longer enhanced by subsequent increases in 1,4-benzenedimethanethiol concentration. After heating at $60^{\circ} \mathrm{C}$ for $24 \mathrm{~h}$, the samples showed similar results. Using biphenyl-4,4' -dithiol molecule cross-linked CdSe/ZnS QDs, it appeared the optical properties of CdSe/ZnS QDs may be related to the solubility of biphenyl-4, $4^{\prime}$-dithiol in toluene solvents. Biphenyl-4, $4^{\prime}$-dithiol solubility in toluene is limited; when the molar ratio of CdSe/ZnS QDs to biphenyl$4,4^{\prime}$-dithiol is decreased to $1: 2$, biphenyl-4,4'-dithiol will precipitate in solution. In the meantime, some QDs are absorbed on the surface of dithiol molecular, which affects the equilibrium of the solution. After heat treatment at $60^{\circ} \mathrm{C}$ for $24 \mathrm{~h}$, perhaps due to increasing solubility of biphenyl- $4,4^{\prime}$ dithiol in toluene, the optical properties of CdSe/ZnS QDs system are the best when the molar ratio of QDs to thiol is 1:2 (see Table 3). Experimental results show that optical properties of CdSe/ZnS QDs are enhanced until the molar ratio 
TABle 3: Optical properties of thiol-linked CdSe/ZnS QDs before and after heat treatment at $60^{\circ} \mathrm{C}$ for $24 \mathrm{~h}$ under light with no inert gas protection.

\begin{tabular}{|c|c|c|c|}
\hline Linkers & Molar ratio of CdSe/ZnS QDs to linkers & QY of QDs before heating (\%) & QY of Qds after heating (\%) \\
\hline \multirow{4}{*}{ 1,4-Benzenedimethanethiol (BMT) } & $4: 1$ & 23.4 & 17.1 \\
\hline & $2: 1$ & 30.1 & 23.4 \\
\hline & $1: 2$ & 26.9 & 28.1 \\
\hline & $1: 8$ & 25.9 & 27.0 \\
\hline \multirow{4}{*}{ Biphenyl-4,4'-dithiol (BPDT) } & $4: 1$ & 20.0 & 18.8 \\
\hline & $2: 1$ & 19.6 & 21.7 \\
\hline & $1: 2$ & 19.4 & 25.1 \\
\hline & $1: 8$ & 33.6 & 13.0 \\
\hline \multirow{4}{*}{ 1,16-Hexadecanedithiol } & $4: 1$ & 30.2 & 22.7 \\
\hline & $2: 1$ & 25.6 & 22.1 \\
\hline & $1: 2$ & 27.7 & 29.1 \\
\hline & $1: 8$ & 27.7 & 29.1 \\
\hline \multirow{4}{*}{ 1,11-Undecanedithiol } & $4: 1$ & 23.5 & 20.1 \\
\hline & $2: 1$ & 25.7 & 25.1 \\
\hline & $1: 2$ & 25.9 & 25.9 \\
\hline & $1: 8$ & 27.0 & 29.2 \\
\hline \multirow{4}{*}{ 11-Mercapto-1-undecanol } & $4: 1$ & 21.3 & 18.5 \\
\hline & $2: 1$ & 21.9 & 18.8 \\
\hline & $1: 2$ & 23.4 & 21.2 \\
\hline & $1: 8$ & 27.1 & 29.0 \\
\hline \multirow{4}{*}{ 1,8-Octanedithiol (ODT) } & $4: 1$ & 22.9 & 20.8 \\
\hline & $2: 1$ & 24.2 & 24.8 \\
\hline & $1: 2$ & 25.5 & 27.5 \\
\hline & $1: 8$ & 23.9 & 26.8 \\
\hline No linker & - & 20.7 & 12.6 \\
\hline
\end{tabular}

of CdSe/ZnS QDs to 1,16-hexadecanedithiol, aliphatic chain thiol, decreases to $2: 1$. Then, as the molar ratio of $\mathrm{CdSe} / \mathrm{ZnS}$ QDs to 1,16-hexadecanedithiol continues to decrease, the optical properties achieve stability. With heat treatment at $60^{\circ} \mathrm{C}$ for $24 \mathrm{~h}$, the optical properties are enhanced until the molar ratio of CdSe/ZnS QDs to 1,16-hexadecanedithiol decreases to $1: 2$. Then, as the molar ratio of $\mathrm{CdSe} / \mathrm{ZnS}$ QDs to 1,16-hexadecanedithiol continues to decrease, the optical properties achieve stability. The optical properties of CdSe/ZnS QDs cross-linked with 1,11-undecanedithiol are better than those with 1,16-hexadecanedithiol. Experimental results show that optical properties of CdSe/ZnS QDs are enhanced until the molar ratio of CdSe/ZnS QDs to 1,11undecanedithiol decreases to $2: 1$. Then, as the molar ratio of $\mathrm{CdSe} / \mathrm{ZnS}$ QDs to 1,11-undecanedithiol continues to decrease, the optical properties achieve stability. Similar results were obtained after the QDs system was heated at $60^{\circ} \mathrm{C}$ for $24 \mathrm{~h}$. When 1,8-octanedithiol served as a linker, similar results were observed.

The passivation effect of 11-mercapto-1-undecanol is not as good as the effect of dithiols but better than the case with no linker in CdSe/ZnS QDs system. Data in Table 3 show that the optical properties of CdSe/ZnS QDs are enhanced as the molar ratio of $\mathrm{CdSe} / \mathrm{ZnS} \mathrm{QDs}$ to 11 -mercapto-1undecanol decreases. After heat treatment at $60^{\circ} \mathrm{C}$ for $24 \mathrm{~h}$, similar results were obtained and the protective function of 11-mercapto-1-undecanol was effective when the molar ratio of CdSe/ZnS QDs to 11-mercapto-1-undecanol decreased to $1: 8$.

Based on the above experimental results, it was found that the optical properties of CdSe/ZnS QDs cross-linked with dithiols are better than those cross-linked with hydroxy thiol molecules, and that the modified effect of dithiol with aliphatic or aromatic chain on their optical properties is similar. Using 1,4-benzenedimethanethiol as a linker, and after heating at $60^{\circ} \mathrm{C}$ for $24 \mathrm{~h}$, the optical properties of $\mathrm{CdSe} / \mathrm{ZnS}$ QDs were not as good as those obtained using dithiol with an aliphatic chain, although the defect luminescence was also the weakest.

Aldana et al. [55] reported on the use of thiol molecules to increase the stability of the optical properties of CdSe QDs. Due to the presence of the thiol molecules, oxidation of the CdSe QDs was prevented. Koole et al. [56] found that dithiol can be used to cross-link CdTe QDs. Our experimental results here also show that dithiol molecules may cross-link $\mathrm{CdSe} / \mathrm{ZnS}$ QDs (and thus form dimers and trimers per STEM images). However, at the same time, the dithiols keep QDs apart with molecular interspacing and avoid their further aggregation, resulting in a more stable optical performance. 
A longer thermal treatment time was studied. Our experimental results showed that longer thermal treatment did not improve the protective effect to quantum dots but did provide a means of accelerating the replacement of the ligands. Thermal treatment has also accelerated the oxidation and precipitation of quantum dots, which are not beneficial to their optical properties. The experimental results showed that ODT obviously protected the quantum dots and thus improved their stability under heating or long-term storage conditions, but if heating was continued for long periods, such as $144 \mathrm{~h}$ as shown in Figure 10, the protective ability was not as effective as that obtained at room temperature.

\section{Conclusions}

In summary, the core shell structure of CdSe/ZnS quantum dots was synthesized successfully and used in studies of ligand exchange and coupling and their effect on the optical properties of ligand-modified QDs. During synthesis, the reaction conditions were investigated. As the growth time increased, the photoluminescence emission intensity of CdSe quantum dots likewise increased. According to our experimental results, the PL emission of QDs was greatly improved after adding the zinc and sulfur precursors.

Furthermore, thiol molecules acted not only as coligands to passivate the QD surface but also possibly as molecular linkers between QDs to improve the optical properties of the QD system. Thiol ligand molecules replaced part of TOPO and another kind of phosphorus in the quantum systems, which comes from the impurities of TOPO and TOP. Under different conditions, the optical properties of core-shell structure $\mathrm{CdSe} / \mathrm{ZnS}$ quantum dots were enhanced by cross-linked thiol molecules such as 1,4-benzenedimethanethiol, biphenyl-4,4 ${ }^{\prime}$-dithiol, 1,16hexadecanedithiol, 1,11-undecanedithiol, 1,8-octanedithiol, and 11-mercapto-1-undecanol. The optical properties of $\mathrm{CdSe} / \mathrm{ZnS}$ QDs cross-linked with dithiol were better than hydroxy thiol molecules, and the modified effect of dithiol with an aliphatic or aromatic chain on the optical properties was similar. The optical properties of linked $\mathrm{CdSe} / \mathrm{ZnS}$ QDs showed no change after 1 week at room temperature. And the results shows that the optical properties of CdSe/ZnS QDs cross-linked with small molecules, such as 1,11-undecanedithiol and 1,8-octanedithiol, is better than cross-linked with larger molecules such as1,4benzenedimethanethiol after heat treatment at $60^{\circ} \mathrm{C}$ for $24 \mathrm{~h}$.

\section{Conflict of Interests}

The authors declare that there is no conflict of interests regarding the publication of this paper.

\section{Acknowledgments}

The authors would like to thank their colleagues at the Oak Ridge National Laboratory (ORNL), particularly Edward \{Ed\} W. Hagaman and Jian Jiao for providing NMR measurements and Reza T. Dabestani for giving access to the UV-Vis absorption and photoluminescence spectrometers. Thanks are also due to E. Andrew Payzant for XRD data, Lawrence Frederick Allard Jr. for data obtained from the ACEM at the ORNL HTML user facility, and David C. Joy for data obtained from the STEM at the ORNL/CNMS user facility. This work was supported in part by the Laboratory Directed Research and Development Program (Seed Money project) of ORNL, which is managed by UT-Battelle, LLC, for the U.S. Department of Energy, and NA22 program. The authors would also like to acknowledge China Scholarship Council and China National Natural Science Foundation for providing the financial support to $\mathrm{Ph}$.D. student candidate Huaping Zhu.

\section{References}

[1] S. A. Claridge, A. W. Castleman Jr., S. N. Khanna, C. B. Murray, A. Sen, and P. S. Weiss, "Cluster-assembled materials", ACS Nano, vol. 3, no. 2, pp. 244-255, 2009.

[2] I. L. Medintz, H. T. Uyeda, E. R. Goldman, and H. Mattoussi, "Quantum dot bioconjugates for imaging, labelling and sensing," Nature Materials, vol. 4, no. 6, pp. 435-446, 2005.

[3] W. Liu, M. Howarth, A. B. Greytak et al., "Compact biocompatible quantum dots functionalized for cellular imaging," Journal of the American Chemical Society, vol. 130, no. 4, pp. 1274-1284, 2008.

[4] J. J. Li, Y. A. Wang, W. Guo et al., "Large-scale synthesis of nearly monodisperse $\mathrm{CdSe} / \mathrm{CdS}$ core/shell nanocrystals using air-stable reagents via successive ion layer adsorption and reaction," Journal of the American Chemical Society, vol. 125, no. 41, pp. 12567-12575, 2003.

[5] Z. A. Peng and X. Peng, "Mechanisms of the shape evolution of CdSe nanocrystals," Journal of the American Chemical Society, vol. 123, no. 7, pp. 1389-1395, 2001.

[6] B.-K. Pong, B. L. Trout, and J.-Y. Lee, "Modified ligandexchange for efficient solubilization of CdSe/ZnS quantum dots in water: a procedure guided by computational studies," Langmuir, vol. 24, no. 10, pp. 5270-5276, 2008.

[7] S. Hohng and T. Ha, "Near-complete suppression of quantum dot blinking in ambient conditions," Journal of the American Chemical Society, vol. 126, no. 5, pp. 1324-1325, 2004.

[8] S. Jeong, M. Achermann, J. Nanda, S. Ivanov, V. I. Klimov, and J. A. Hollingsworth, "Effect of the thiol-thiolate equilibrium on the photophysical properties of aqueous $\mathrm{CdSe} / \mathrm{ZnS}$ nanocrystal quantum dots," Journal of the American Chemical Society, vol. 127, no. 29, pp. 10126-10127, 2005.

[9] V. Fomenko and D. J. Nesbitt, "Solution control of radiative and nonradiative lifetimes: a novel contribution to quantum dot blinking suppression," Nano Letters, vol. 8, no. 1, pp. 287-293, 2008.

[10] C. Landes, C. Burda, M. Braun, and M. A. El-Sayed, "Photoluminescence of CdSe nanoparticles in the presence of a hole acceptor: N-butylamine," Journal of Physical Chemistry B, vol. 105, no. 15, pp. 2981-2986, 2001.

[11] G. Kalyuzhny and R. W. Murray, "Ligand effects on optical properties of CdSe nanocrystals," Journal of Physical Chemistry $B$, vol. 109, no. 15, pp. 7012-7021, 2005.

[12] J. A. Gaunt, A. E. Knight, S. A. Windsor, and V. Chechik, "Stability and quantum yield effects of small molecule additives on solutions of semiconductor nanoparticles," Journal of Colloid and Interface Science, vol. 290, no. 2, pp. 437-443, 2005. 
[13] C. Bullen and P. Mulvaney, "The effects of chemisorption on the luminescence of CdSe quantum dots," Langmuir, vol. 22, no. 7, pp. 3007-3013, 2006.

[14] A. M. Munro, I. J.-L. Plante, M. S. Ng, and D. S. Ginger, "Quantitative study of the effects of surface ligand concentration on CdSe nanocrystal photoluminescence," Journal of Physical Chemistry C, vol. 111, no. 17, pp. 6220-6227, 2007.

[15] D. E. Gómez, J. van Embden, J. Jasieniak, T. A. Smith, and P. Mulvaney, "Blinking and surface chemistry of single CdSe nanocrystals," Small, vol. 2, no. 2, pp. 204-208, 2006.

[16] N. I. Hammer, K. T. Early, K. Sill, M. Y. Odoi, T. Emrick, and M. D. Barnes, "Coverage-mediated suppression of blinking in solid state quantum dot conjugated organic composite nanostructures," Journal of Physical Chemistry B, vol. 110, no. 29, pp. 14167-14171, 2006.

[17] M. Y. Odoi, N. I. Hammer, K. T. Early et al., "Fluorescence lifetimes and correlated photon statistics from single CdSe/oligo(phenylene vinylene) composite nanostructures," Nano Letters, vol. 7, no. 9, pp. 2769-2773, 2007.

[18] S. F. Wuister, C. de Mello Donegá, and A. Meijerink, "Influence of thiol capping on the exciton luminescence and decay kinetics of CdTe and CdSe quantum dots," Journal of Physical Chemistry $B$, vol. 108, no. 45, pp. 17393-17397, 2004.

[19] X. Ji, D. Copenhaver, C. Sichmeller, and X. Peng, "Ligand bonding and dynamics on colloidal nanocrystals at room temperature: the case of alkylamines on CdSe nanocrystals," Journal of the American Chemical Society, vol. 130, no. 17, pp. 5726-5735, 2008.

[20] V. V. Breus, C. D. Heyes, and G. U. Nienhaus, "Quenching of CdSe-ZnS core-shell quantum dot luminescence by watersoluble thiolated ligands," Journal of Physical Chemistry C, vol. 111, no. 50, pp. 18589-18594, 2007.

[21] J. A. Kloepfer, S. E. Bradforth, and J. L. Nadeau, "Photophysical properties of biologically compatible CdSe quantum dot structures," Journal of Physical Chemistry B, vol. 109, no. 20, pp. 999610003, 2005.

[22] W. Jiang, S. Mardyani, H. Fischer, and W. C. W. Chan, "Design and characterization of lysine cross-linked mercapto-acid biocompatible quantum dots," Chemistry of Materials, vol. 18, no. 4, pp. 872-878, 2006.

[23] B. Zaman, T. N. Baral, J. Zhang, D. Whitfield, and K. Yu, "Singledomain antibody functionalized CdSe/ZnS quantum dots for cellular imaging of cancer cells," Journal of Physical Chemistry C, vol. 113, no. 2, pp. 495-499, 2009.

[24] C. Xu, K. Xu, H. Gu et al., "Nitrilotriacetic acid-modified magnetic nanoparticles as a general agent to bind histidinetagged proteins," Journal of the American Chemical Society, vol. 126, no. 11, pp. 3392-3393, 2004.

[25] R. Hong, N. O. Fischer, T. Emrick, and V. M. Rotello, "Surface PEGylation and ligand exchange chemistry of FePt nanoparticles for biological applications," Chemistry of Materials, vol. 17, no. 18, pp. 4617-4621, 2005.

[26] D. B. Robinson, H. H. J. Persson, H. Zeng et al., "DNAfunctionalized $\mathrm{MFe}_{2} \mathrm{O}_{4}(\mathrm{M}=\mathrm{Fe}, \mathrm{Co}$, or $\mathrm{Mn})$ nanoparticles and their hybridization to DNA-functionalized surfaces," Langmuir, vol. 21, no. 7, pp. 3096-3103, 2005.

[27] J. M. Haremza, M. A. Hahn, T. D. Krauss, S. Chen, and J. Calcines, "Attachment of single CdSe nanocrystals to individual single-walled carbon nanotubes," Nano Letters, vol. 2, no. 11, pp. 1253-1258, 2002.

[28] S. J. Rosenthal, I. Tomlinson, E. M. Adkins et al., "Targeting cell surface receptors with ligand-conjugated nanocrystals," Journal of the American Chemical Society, vol. 124, no. 17, pp. 4586-4594, 2002.

[29] A. C. Templeton, S. Chen, S. M. Gross, and R. W. Murray, "Water-soluble, isolable gold clusters protected by tiopronin and coenzyme a monolayers," Langmuir, vol. 15, no. 1, pp. 66-76, 1999.

[30] Y. Negishi, K. Nobusada, and T. Tsukuda, "Glutathioneprotected gold clusters revisited: bridging the gap between gold(I)-thiolate complexes and thiolate-protected gold nanocrystals," Journal of the American Chemical Society, vol. 127, no. 14, pp. 5261-5270, 2005.

[31] M. P. Rowe, K. E. Plass, K. Kim, Ç. Kurdak, E. T. Zellers, and A. J. Matzger, "Single-phase synthesis of functionalized gold nanoparticles," Chemistry of Materials, vol. 16, no. 18, pp. 35133517, 2004.

[32] K. Yu, S. Singh, N. Patrito, and V. Chu, "Effect of reaction media on the growth and photoluminescence of colloidal CdSe nanocrystals," Langmuir, vol. 20, no. 25, pp. 11161-11168, 2004.

[33] K. Yu, B. Zaman, S. Romanova, D.-S. Wang, and J. A. Ripmeester, "Sequential synthesis of type II colloidal CdTe/CdSe core-shell nanocrystals," Small, vol. 1, no. 3, pp. 332-338, 2005.

[34] L. Qu and X. J. Peng, "Control of photoluminescence properties of CdSe nanocrystals in growth," Journal of the American Chemical Society, vol. 124, no. 9, pp. 2049-2055, 2004.

[35] K. Yu, B. Zaman, S. Singh, D. Wang, and J. A. Ripmeester, "The effect of dispersion media on photoluminescence of colloidal CdSe nanocrystals synthesized from TOP," Chemistry of Materials, vol. 17, no. 10, pp. 2552-2561, 2005.

[36] X. Peng, T. E. Wilson, A. P. Alivisatos, and P. G. Schultz, "Synthesis and isolation of a homodimer of cadmium selenide nanocrystals," Angewandte Chemie-International Edition, vol. 36, no. 1-2, pp. 145-147, 1997.

[37] S. Pathak, S.-K. Choi, N. Arnheim, and M. E. Thompson, "Hydroxylated quantum dots as luminescent probes for in situ hybridization," Journal of the American Chemical Society, vol. 123, no. 17, pp. 4103-4104, 2001.

[38] H. Mattoussi, J. M. Mauro, E. R. Goldman et al., "Self-assembly of CdSe-ZnS quantum dot bioconjugates using an engineered recombinant protein," Journal of the American Chemical Society, vol. 122, no. 49, pp. 12142-12150, 2000.

[39] W. C. W. Chan and S. Nie, "Quantum dot bioconjugates for ultrasensitive nonisotopic detection," Science, vol. 281, no. 5385, pp. 2016-2018, 1998.

[40] M. Bruchez Jr., M. Moronne, P. Gin, S. Weiss, and A. P. Alivisatos, "Semiconductor nanocrystals as fluorescent biological labels," Science, vol. 281, no. 5385, pp. 2013-2016, 1998.

[41] I. L. Medintz, H. T. Uyeda, E. R. Goldman, and H. Mattoussi, "Quantum dot bioconjugates for imaging, labelling and sensing," Nature Materials, vol. 4, no. 6, pp. 435-446, 2005.

[42] J. J. Storhoff and C. A. Mirkin, "Programmed materials synthesis with DNA," Chemical Reviews, vol. 99, no. 7, pp. 1849-1862, 1999.

[43] C. J. Loweth, W. B. Caldwell, X. Peng, A. P. Alivisatos, and P. G. Schultz, "DNA-based assembly of gold nanocrystals," Angewandte Chemie-International Edition, vol. 38, no. 12, pp. 1808-1812, 1999.

[44] R. L. Whetten, M. N. Shafigullin, J. T. Khoury et al., "Crystal structures of molecular gold nanocrystal arrays," Accounts of Chemical Research, vol. 32, no. 5, pp. 397-406, 1999.

[45] M. J. Hostetler, S. J. Green, J. J. Stokes, and R. W. Murray, "Monolayers in three dimensions: synthesis and electrochemistry of $\omega$-functionalized alkanethiolate-stabilized gold cluster 
compounds," Journal of the American Chemical Society, vol. 118, no. 17, pp. 4212-4213, 1996.

[46] A. Eychmuller, A. Hasselbath, L. Katsikas, and H. Weller, "Photochemistry of semiconductor colloids. 36. Fluorescence investigations on the nature of electron and hole traps in Qsized colloidal CdS particles," Berichte der Bunsengesellschaft für Physikalische Chemie, vol. 95, no. 1, pp. 79-84, 1991.

[47] M. Nirmal, C. B. Murray, D. J. Norris, and M. G. Bawendi, "Surface electronic properties of CdSe nanocrystallites," Zeitschrift für Physik D, vol. 26, no. 1, pp. 361-363, 1993.

[48] M. L. Steigerwald, A. P. Alivisatos, J. M. Gibson et al., "Surface derivatization and isolation of semiconductor cluster molecules," Journal of the American Chemical Society, vol. 110, no. 10, pp. 3046-3050, 1988.

[49] C. B. Murray, D. J. Norris, and M. G. Bawendi, "Synthesis and characterization of nearly monodisperse $\mathrm{CdE}(\mathrm{E}=\mathrm{S}$, Se, $\mathrm{Te})$ semiconductor nanocrystallites," Journal of the American Chemical Society, vol. 115, no. 19, pp. 8706-8715, 1993.

[50] M. G. Bawendi, A. R. Kortan, M. L. Steigerwald, and L. E. Brus, "X-ray structural characterization of larger CdSe semiconductor clusters," The Journal of Chemical Physics, vol. 91, no. 11, pp. 7282-7290, 1989.

[51] A. M. Thayer, M. L. Steigerwald, T. M. Duncan, and D. C. Douglass, "NMR study of semiconductor molecular clusters," Physical Review Letters, vol. 60, no. 25, pp. 2673-2676, 1988.

[52] J. R. Sachleben, E. Wrenn Wooten, L. Emsley, A. Pines, V. L. Colvin, and A. P. Alivisatos, "NMR studies of the surface structure and dynamics of semiconductor nanocrystals," Chemical Physics Letters, vol. 198, no. 5, pp. 431-436, 1992.

[53] L. R. Becerra, C. B. Murray, R. G. Griffin, and M. G. Bawendi, "Investigation of the surface morphology of capped CdSe nanocrystallites by 31P nuclear magnetic resonance," The Journal of Chemical Physics, vol. 100, no. 4, pp. 3297-3300, 1994.

[54] Z. A. Peng and X. Peng, "Mechanisms of the shape evolution of CdSe nanocrystals," Journal of the American Chemical Society, vol. 123, no. 7, pp. 1389-1395, 2001.

[55] J. Aldana, Y. A. Wang, and X. Peng, "Photochemical instability of CdSe nanocrystals coated by hydrophilic thiols," Journal of the American Chemical Society, vol. 123, no. 36, pp. 8844-8850, 2001.

[56] R. Koole, B. Luigjes, M. Tachiya et al., "Differences in cross-link chemistry between rigid and flexible dithiol molecules revealed by optical studies of CdTe quantum dots," Journal of Physical Chemistry C, vol. 111, no. 30, pp. 11208-11215, 2007. 

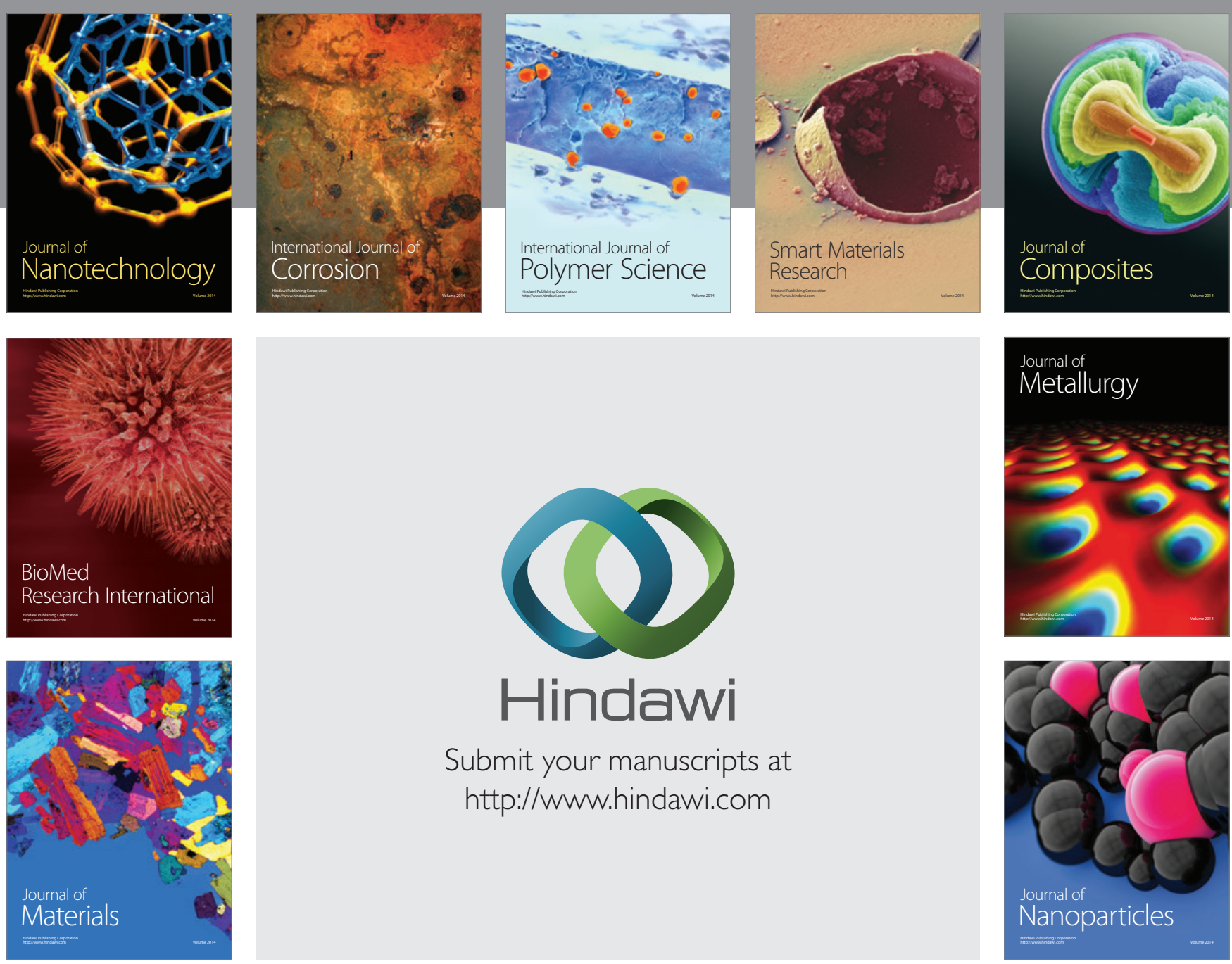

Submit your manuscripts at http://www.hindawi.com
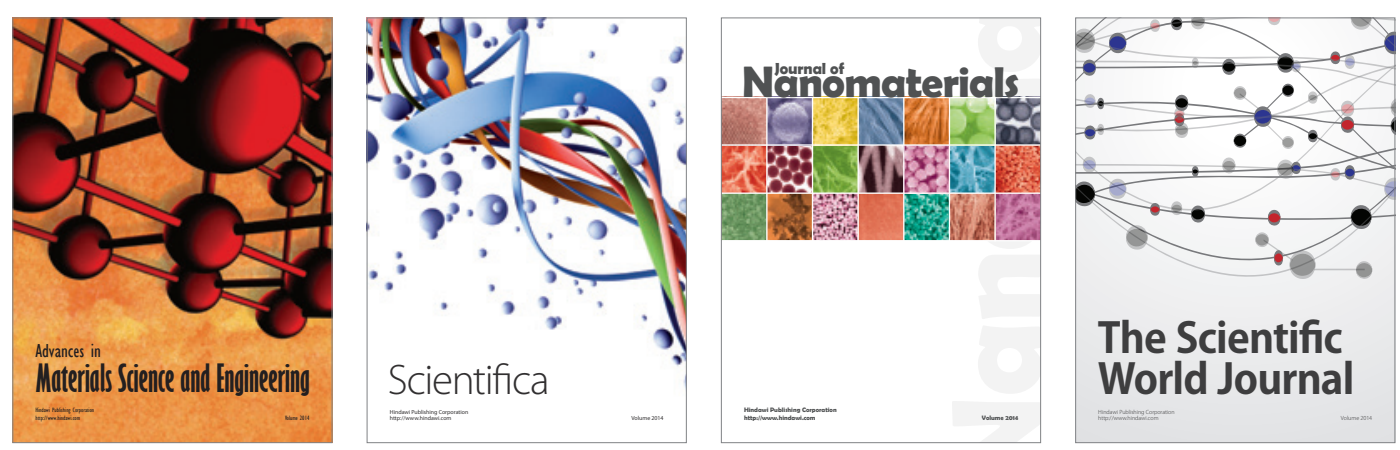

\section{The Scientific World Journal}
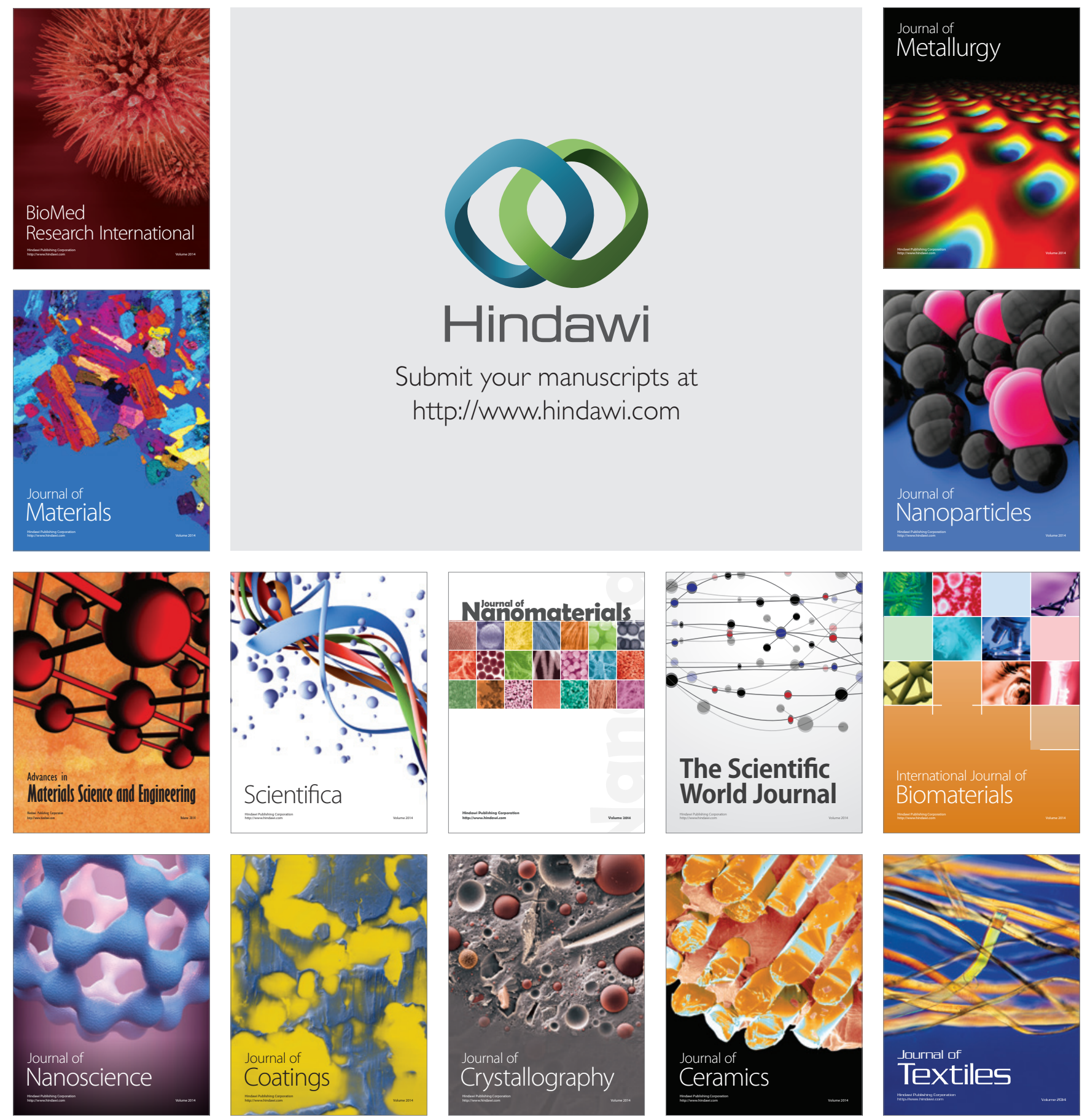